\title{
Emerging Materials for Lowering Atmospheric Carbon
}

Balaka Barkakaty ${ }^{1}$, ${ }^{*}$ Bobby G. Sumpter ${ }^{1}$, Ilia N. Ivanov ${ }^{1}$, Matthew E. Potter ${ }^{2}$, Christopher W. Jones $^{2}$, and Bradley S. Lokitz ${ }^{1 *}$

${ }^{1}$ Center for Nanophase Materials Sciences, Oak Ridge National Laboratory, One Bethel Valley Road, Oak Ridge, TN 37831, USA

${ }^{2}$ School of Chemical \& Biomolecular Engineering, Georgia Institute of Technology, Atlanta, GA 30332

E-mail: barkakatyb@ornl.gov or lokitzbs@ornl.gov

[This manuscript has been authored by UT-Battelle, LLC under Contract No. DE-AC05-000R22725 with the U.S. Department of Energy. The United States Government retains and the publisher, by accepting the article for publication, acknowledges that the United States Government retains a non-exclusive, paid-up, irrevocable, world-wide license to publish or reproduce the published form of this manuscript, or allow others to do so, for United States Government purposes. The Department of Energy will provide public access to these results of federally sponsored research in accordance with the DOE Public Access Plan (http://energy.gov/downloads/doe-public-access-plan).] 


\section{ABSTRACT}

$\mathrm{CO}_{2}$ emissions from anthropogenic sources and the rate at which they increase could have deep global ramifications such as irreversible climate change and increased natural disasters. Because greater than $50 \%$ of anthropogenic $\mathrm{CO}_{2}$ emissions come from small, distributed sectors such as homes, offices, and transportation sources, most renewable energy systems and on-site carbon capture technologies for reducing future $\mathrm{CO}_{2}$ emissions cannot be effectively utilized. This problem might be mediated by considering novel materials and technologies for directly capturing/removing $\mathrm{CO}_{2}$ from air. However, compared to materials for capturing $\mathrm{CO}_{2}$ at on-site emission sources, materials for capturing $\mathrm{CO}_{2}$ directly from air must be more selective to $\mathrm{CO}_{2}$, and should operate and be stable at near ambient conditions. In this review article, we briefly summarize the recent devlopments in materials for capturing carbon dioxide directly from air. We discuss the challenges in this field and offer a perspective for developing the current state-ofart and also highlight the potential of a few recent discoveries in materials science that show potential for advanced application of air capture technology.

\section{Keywords}

Direct Air Capture, Negative Emissions, Independent of Emitting Source, Experimental-Theory Approach, Optimized Properties

\section{Contents}

1. Introduction

2. Overview of $\mathrm{CO}_{2}$ sorbent materials

2.1 Inorganic Sorbents

2.2 Zeolites 
2.3 Metal-Organic Frameworks (MOFs)

2.4 Microporous Organic Polymers (MOPs)

2.5 Activated Carbon

2.5.1 Microporous Carbon

2.5.2 Carbon Nanomaterials

2.5.3 Hetero-atom Activated Carbon

2.6 Supported Amine-Sorbents

3. Outlook and Conclusions

Acknowledgements

References

\section{Introduction}

Carbon dioxide $\left(\mathrm{CO}_{2}\right)$ emission from anthropogenic sources such as fossil fuels exceeded $9.8 \pm 0.5 \mathrm{Gt}$ tons (carbon) in 2014 , at an average rate of $109.9 \pm 0.3 \mathrm{Mt}$ C/year as shown in Figure 1 (Boden et al. 2015). Natural carbon sinks, such as oceans and land, captures atmospheric $\mathrm{CO}_{2}$ at a much slower rate of $57.6 \pm 0.94 \mathrm{Mt} \mathrm{C} /$ year, and therefore cannot offset anthropogenic $\mathrm{CO}_{2}$ emissions. This leads to an increase in the concentration of $\mathrm{CO}_{2}$ in the atmosphere at an average rate of 52.3+0.91 Mt C/year as shown in Figure 2 (C. Le Quéré et al. 2015). 


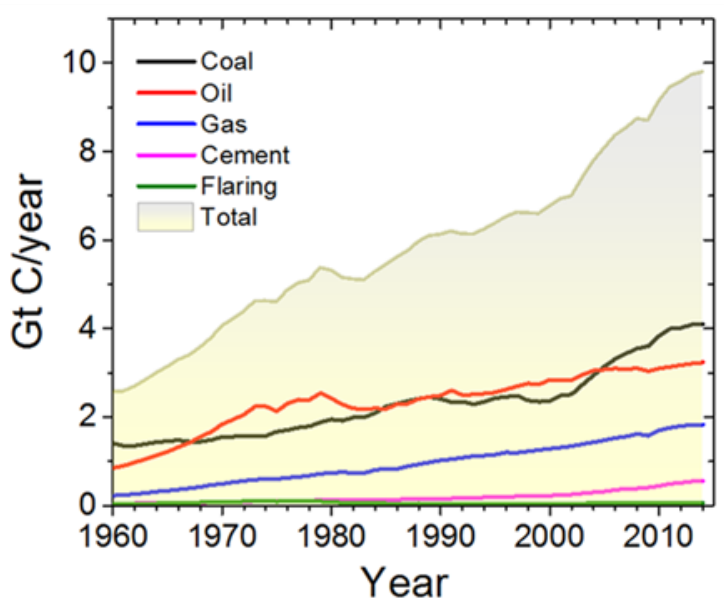

Figure 1. Trends of increasing $\mathrm{CO}_{2}$ emission from various anthropogenic sources as a function of time measured from 1960.

Data Source: Boden, T. A., Marland, G., Andres, R. J. 2010. Global, regional, and National Fossil-Fuel $\mathrm{CO}_{2}$ Emissions. Carbon Dioxide Information Analysis Center, Oak Ridge National laboratory, U.S Department of Energy, Oak Ridge, Tenn., U.S.A. doi 10.3334/CDIAC/00001_V2010

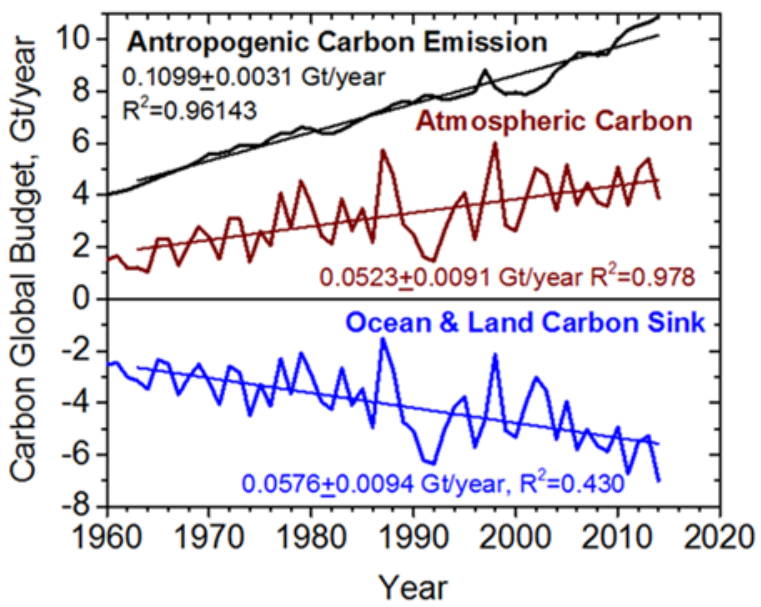

Figure 2. Global carbon budget as a function of time for emissions from anthropogenic sources and their uptake by natural carbon sinks.

Data Source: C. Le Quéré et al. Earth Sys. Sci. Data 2015, 7, 349-396. http://www.earth-syst-sci-data.net/7/349/2015/essd-7-349-2015.pdf

If the steady rise in $\mathrm{CO}_{2}$ emission continues, and technologies capable of removing $\mathrm{CO}_{2}$ from the atmosphere faster than nature are not implemented, irreversible climate change could occur causing negative consequences which could include loss of habitat, food shortages, and increasing occurrences of natural disasters. To decrease $\mathrm{CO}_{2}$ emissions by $30-85 \%$, a target was set by the Intergovernmental Panel on Climate Change (IPCC) that coal-based emissions (a major contributor to anthropogenic emission, Figure 1) must be completely eliminated by 2050 and the emissions from other fossil fuel sources have to be substantially reduced (Kharecha and Hansen, 2008). However, state-of-art alternative energy sources such as biomass fuels, geothermal energy, solar energy, and wind energy cannot currently provide the energy needed to satisfy global demand (Lackner, 2005; Lund, 2007). 
Moreover, renewable energy systems and carbon capture technologies to reduce future $\mathrm{CO}_{2}$ emissions cannot curb the current climate risks caused by the $\mathrm{CO}_{2}$ that is already in the atmosphere. Therefore, the strategic adoption and implementation of a hybrid approach based on a renewable and energy efficient infrastructure, combined with carbon capture technologies from on-site emissions as well as from air, is required to combat the climate challenge (Lackner, 2005; Lund, 2007; Lackner, 2012; Jones, 2011; Goeppert et al., 2012). More than 50\% of anthropogenic $\mathrm{CO}_{2}$ emissions come from distributed sources such as home and office heating and cooling, and the transportation sector (International Energy Agency (IEA) Statistics, 2014). To substantially reduce $\mathrm{CO}_{2}$ emissions from anthropogenic sources, implementation of carbon capture and sequestration (CCS) technologies at on-site large fossil fuel-based power plants, as well as in numerous small distributed sources such as cars, trucks, airplanes, homes, and offices would be necessary. However, in most cases installing individual carbon capture units is not practical or cost-effective for distributed sources. For example, capturing $\mathrm{CO}_{2}$ from on-board ground-based vehicles is technically feasible but after the $\mathrm{CO}_{2}$ is captured, it would have to be transported to a sequestration site, requiring extensive and costly infrastructure. Capturing $\mathrm{CO}_{2}$ on-board from airplanes is more complicated due to the added weight from the captured $\mathrm{CO}_{2}$. Similar to ground-based vehicles, installing CCS units in homes and offices would also involve cost challenges associated with infrastructure (Goeppert et al. 2012). Given the high percentage of $\mathrm{CO}_{2}$ emissions from small and distributed sources (Figure 3) coupled with the challenges and high costs associated with CCS, it is clear that other solutions should be explored. 


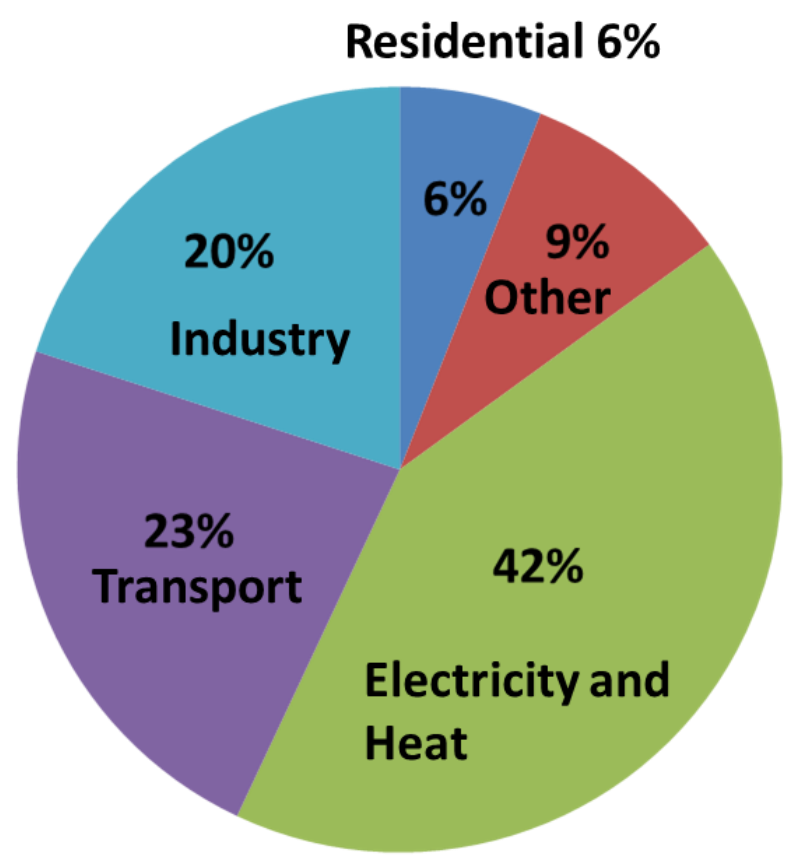

Figure 3. A pie chart breakdown of the global $\mathrm{CO}_{2}$ emissions by sector. *Other: commercial/public services, forestry/agriculture, fishing, energy industries other than electricity and heat generation, and any emissions not mentioned elsewhere.

Data Source: International Energy Agency (IEA) Statistics (2014), $\mathrm{CO}_{2}$ Emissions from Fuel Combustion 2014. Highlights, OECD/IEA, Paris sector (International Energy Agency (IEA) Statistics, 2014).

An alternative solution to $\mathrm{CCS}$, is "air capture," the capture of $\mathrm{CO}_{2}$ directly from the air, which has recently gained significant attention. It addresses the capture challenge without the need for developing extensive $\mathrm{CO}_{2}$-sequestration infrastructure (Jones, 2011; Goeppert et al., 2012). In this approach, the atmosphere serves as the transport medium for $\mathrm{CO}_{2}$ from the site of emission to the site of capture (Jones, 2011; Goeppert et al. 2012; Specht, 1995; Pasel, 2000; Specht, 1999). This separates the $\mathrm{CO}_{2}$ collection process from the $\mathrm{CO}_{2}$ emitting source, unlike a conventional CCS facility. This provides an economic advantage because they can be constructed near the best geological sequestration sites, eliminating the cost attached with building extensive infrastructure for transporting $\mathrm{CO}_{2}$ between emission and sequestration sites. Air capture has additional advantages over conventional CCS which is at best, a "carbon neutral 
process." It aims to remove $\mathrm{CO}_{2}$ from fossil fuel-based power plant emissions, prohibiting further increase in atmospheric $\mathrm{CO}_{2}$ concentration. In contrast, air capture can be viewed as a "carbon negative process" by lowering the $\mathrm{CO}_{2}$ atmospheric concentration from past emissions. Furthermore, when implemented with other $\mathrm{CO}_{2}$ utilization and/or recycling technologies (Figure 4), (Damiani, 2011; Keith, 2006) it may lower the cost for overall $\mathrm{CO}_{2}$ capture and regeneration. Additionally, compared to industrial flue gas, the lower concentration of acid-gas contaminants such as $\mathrm{NO}_{\mathrm{x}}$ and $\mathrm{SO}_{\mathrm{x}}$ in the atmosphere makes air capture an even more attractive strategy to consider (Keith, 2006). 


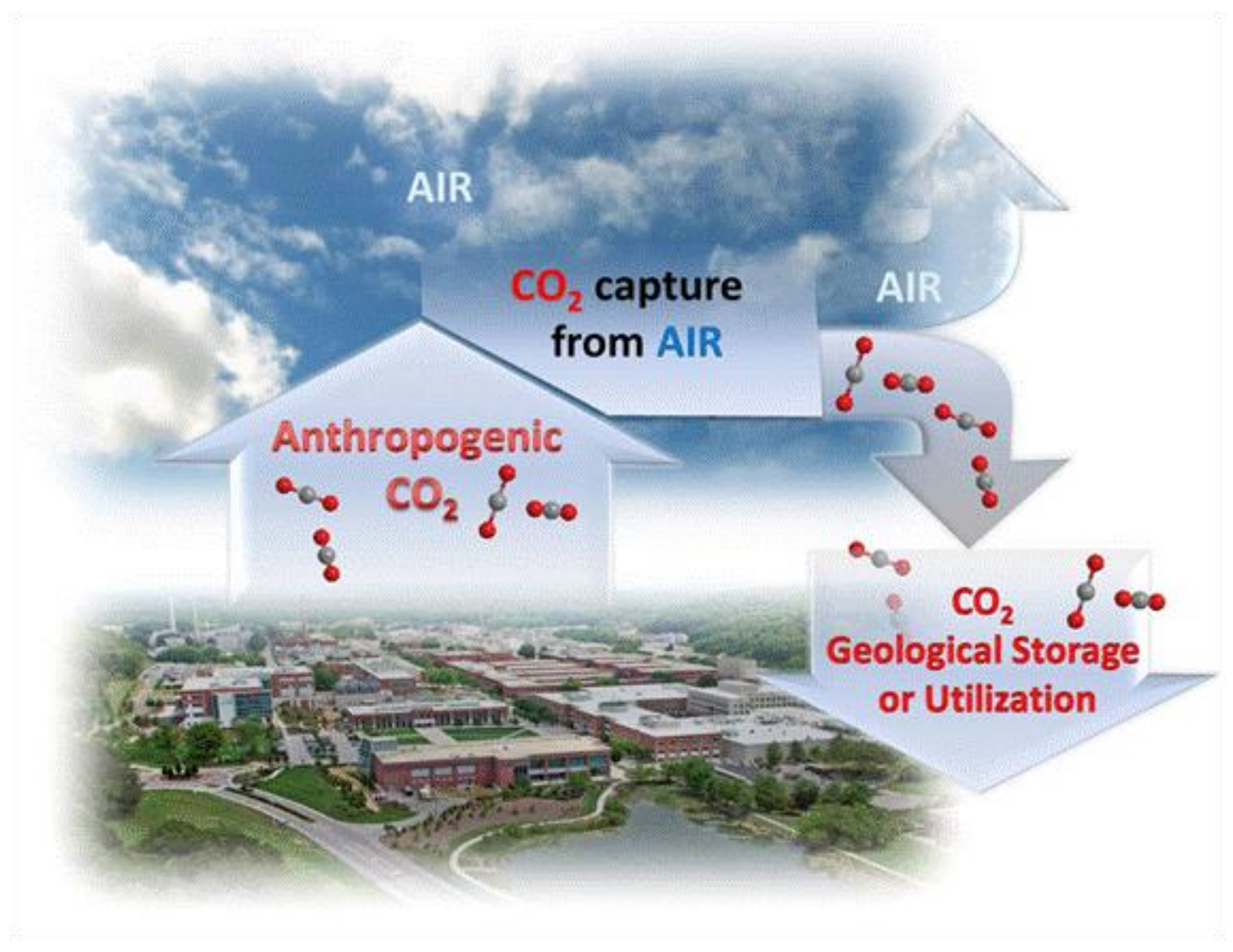

Figure 4. Schematic representation demonstrating the advantage that technologies for capturing $\mathrm{CO}_{2}$ directly from air are independent from the site of $\mathrm{CO}_{2}$ emissions and can be built close to $\mathrm{CO}_{2}$ geological sequestration or utilization sites for lowering the overall cost of $\mathrm{CO}_{2}$ capture.

Footnote: Early approaches for direct air capture (DAC) were energy intensive and were therefore criticized in an early APS report (Direct Air Capture of $\mathrm{CO}_{2}$ with Chemicals, 2016). Obviously, any DAC approach that is not substantially carbon negative is not a viable means for DAC for climate change mitigation purposes.

In this developments article, we highlight current materials for direct $\mathrm{CO}_{2}$ capture from air and discuss recent developments and challenges. We also offer a perspective on the design and development of new and improved air-capture materials by integration of theoretical modeling and experimental methods. 


\section{Overview of $\mathrm{CO}_{2}$ sorbent materials}

\subsection{Inorganic Sorbents}

Inorganic salts such as lithium hydroxide $(\mathrm{LiOH})$ have high $\mathrm{CO}_{2}$ sorption capacities and have been used to capture $\mathrm{CO}_{2}$ directly from air in spacecraft and submarines (Norfleet, 2003; Matty, 2008). Other similar highly basic inorganic candidates include: calcium hydroxide $\left(\mathrm{Ca}(\mathrm{OH})_{2}\right)$, potassium hydroxide $(\mathrm{KOH})$, sodium hydroxide $(\mathrm{NaOH})$, and aqueous solutions of these alkaline sorbents (Lackner et al., 1999; Keith et al., 2010). Recently, “Carbon Engineering,” a start-up company based in Calgary, Canada, has designed a new technology using strong basic hydroxide solutions that capture $100 \mathrm{kt} \mathrm{CO}_{2} / \mathrm{yr}$ directly from air (Holmes et al. 2013). The main advatages of inorganic sorbents is that they are simple, inexpensive, and have minimal environmental risks due to their low vapor pressure (Carbon Engineering, 2015). Carbon Engineering has attracted the attention of private investors such as Bill Gates and Murray Edwards who are providing funding to further improve this technology (Global Warming, 2015). However, $\mathrm{CO}_{2}$ sorbents derived from these metal hydroxides are hindered by the high energy input required to regenerate them for cyclic use. For example, the recovery of a $\mathrm{NaOH}$ solution uses a "caustic recovery" process to regentate the $\mathrm{NaOH}$ from a solution of $\mathrm{Na}_{2} \mathrm{CO}_{3}$ (Jones, 2011; Goeppert et al. 2012; Carbon Engineering, 2015; Mahmoudkhani and Keith, 2009). In this process, the $\mathrm{Na}_{2} \mathrm{CO}_{3}$ solution is reacted with a solution of $\mathrm{Ca}(\mathrm{OH})_{2}$ and forms a $\mathrm{CaCO}_{3}$ precipitate, regenerating the $\mathrm{NaOH}$ solution. $\mathrm{CaCO}_{3}$ is then dried and calcined at a very high temperature $\left(>700{ }^{\circ} \mathrm{C}\right)$ to liberate $\mathrm{CO}_{2}$ and obtain calcium oxide $(\mathrm{CaO}) \cdot \mathrm{Ca}(\mathrm{OH})_{2}$ is regenerated later for the recycling process by the hydration of $\mathrm{CaO}$ (Jones, 2011; Goeppert et al. 2012). The high temperatures needed for regeneration of $\mathrm{NaOH}$ from $\mathrm{Na}_{2} \mathrm{CO}_{3}$ mean the process requires a large energy input and is generally quite expensive. Recently, non-conventional causticization methods such as 
auto-causticization, direct causticization, or partial auto- or direct causticization have gained traction as methods to reduce the cost and energy requirement for regenerating the $\mathrm{CO}_{2}$ capturing inorganic sorbents (Mahmoudkhani and Keith, 2009; Baciocchi et al. 2006; Canadell et al. 2007).

\subsection{Zeolites}

Zeolites are 3-dimensional crystalline aluminosilicate frameworks, which can contain highly basic alkali and alkaline earth elements such as sodium, potassium, and calcium. Zeolites are denoted by the empirical molecular formula: $\mathrm{M}_{2 / \mathrm{n}} \mathrm{O} . \mathrm{Al}_{2} \mathrm{O}_{3} \cdot \mathrm{xSiO}_{2} \cdot \mathrm{yH}_{2} \mathrm{O}$, where $\mathrm{M}=\mathrm{Na}$, $\mathrm{K}$ or $\mathrm{Ca}$; $\mathrm{n}=$ valence of the cation and $\mathrm{x}$ and $\mathrm{y}$ are integers (Hardie et al. 2005). The crystalline structure of zeolites is formed by the sharing of adjacent oxygen atoms in $\mathrm{SiO}_{4}$ and $\mathrm{AlO}_{4}$ tetrahedra (Breck, 1974) creating a network of uniformly sized molecular pores (Breck, 1974; Flanigen, 1991). The isomorphous substitution of aluminum for silicon in the crystalline lattice of zeolites results in a structure with a net negative charge and a high affinity for quadrupolar molecules such as $\mathrm{CO}_{2}$. At ambient temperature and pressure, zeolites can be used for capturing $\mathrm{CO}_{2}$ from air. However competitive adsorption from water, nitrogen, and oxygen, which typically follows the order $\mathrm{H}_{2} \mathrm{O}>\mathrm{CO}_{2}>\mathrm{N}_{2}>\mathrm{O}_{2}$, must be considered (Breck, 1974). For example, Stuckert and Yang reported that a low silica type X zeolite with a high lithium content (Li-LSX) has excellent $\mathrm{CO}_{2}$ adsorption capacity (1.34 mmol $\mathrm{CO}_{2}$ adsorbed/ $\mathrm{g}$ adsorbent $)$ from dry air under ambient conditions (Stuckert, 2011). However, in the presence of $80 \%$ relative humidity, the adsorption capacity is decreased by $96 \%$. Therefore, more robust and moisture stable zeolite systems need to be designed for zeolites to have practical application in capturing $\mathrm{CO}_{2}$ directly from air. Currently, there are a large number of potential structures in the zeolite database that could, in principle, be useful for capturing $\mathrm{CO}_{2}$ (Deem et al. 2011). While it is impractical to synthesize 
every possible structure and investigate its ability to capture $\mathrm{CO}_{2}$, Lin and coworkers employed a computational screening approach to identify potential zeolite and zeolitic imidazolate framework structures for CCS applications (Figure 5) (Lin et al. 2012). Integration of computational methods and synthesis to identify zeolite structures should lead to improved zeolite-based materials for $\mathrm{CO}_{2}$ capture, though the ability to provide high $\mathrm{CO}_{2}$ sorption capacities without competition from water will remain a significant challenge.

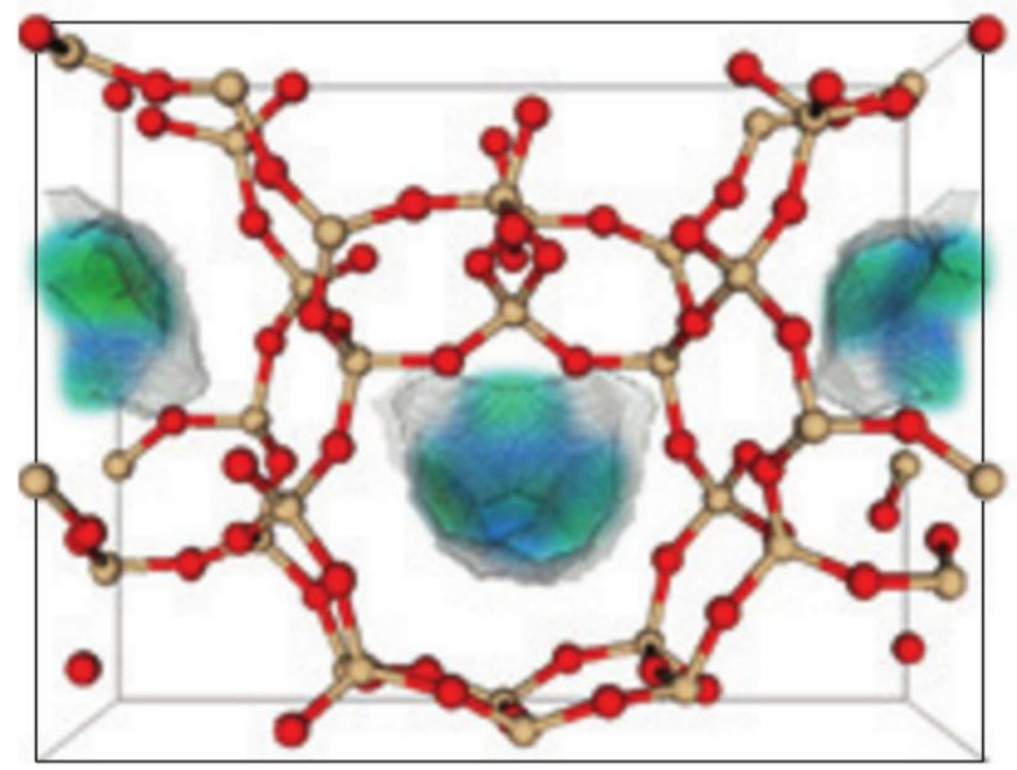

Figure 5. Computational method showing optimal zeolite structure for $\mathrm{CO}_{2}$ capture. Color code: oxygen atoms (red atoms), silicon atoms ( $\tan )$, colored surface (regions in the zeolite pores with high potential for capturing $\mathrm{CO}_{2}$ ).

Reprinted (adapted) by permission from Nature Publishing Group: [Lin, L.-C. et al. Nat. Mat. 2012, 11, 633-641] copyright (2012).

\subsection{Metal-Organic Frameworks (MOFs)}

Similar to zeolites, metal-organic frameworks (MOFs) consist of a porous 3-dimensional crystalline framework, however MOFs are formed by metal ions or a cluster of metal-ions connected by organic linkers (Chen et al., 2001; Cheetham and Rao, 2007; Rowsell et al., 2005; 
Zhao et al., 2004; Eddaoudi et al. 2002; Li et al. 1999). In contrast to zeolites, the organic component of the hybrid structure of MOFs have potential for task-specific design through control of pore architecture and linker functionalization ( $\mathrm{Li}$ et al., 1999). MOFs have recently gained attention due to their excellent $\mathrm{CO}_{2}$ capture efficiency from $\mathrm{CO}_{2}$ emitting sources such as precombustion and post-combustion flue gas, natural gas, and bio gas (Caskey et al., 2008; Sumida et al., 2012; Sayari et al., 2011; Nugent et al., 2013). However, to our knowldege, there are only a few reports detailing MOFs' potential to remove $\mathrm{CO}_{2}$ from ultra-dilute sources through direct air capture (Jones, 2011; Goeppert et al. 2012; Xue et al., 2013; McDonald et al., 2012; Choi et al., 2012; Shekhah et al., 2014; Kumar et al., 2015) . For example, McDonald et al. reported two metal-organic frameworks labelled $\mathrm{M}_{2}$ (dobpdc), where $\mathrm{M}=\operatorname{Zn}(\mathbf{1}), \operatorname{Mg}(\mathbf{2})$ and dobpdc = 4,4'-dioxido-3,3'-biphenyldicarboxylate, functionalized with N,N'dimethylethylenediamine (mmen) results in a compound with excellent $\mathrm{CO}_{2}$ adsorption capacity at low pressures $\left(2.0 \mathrm{mmol} / \mathrm{g}\right.$ at $0.39 \mathrm{mbar}$ at $\left.25{ }^{\circ} \mathrm{C}\right)$ that are comparable to the conditions for direct $\mathrm{CO}_{2}$ capture from air (McDonald et al. 2012). Like zeolites, humidity significantly decreases the efficiency of MOFs which use open metal sites for binding to $\mathrm{CO}_{2}$. However, Shekhah et al. has recently reported a synthetic approach to construct a two dimensional square grid metal-organic framework (SIFSIX-3-Cu) with a pyrazine/copper (II) connected by silicon hexafluoride anions (Figure 6) (Shekhah et al., 2014). The high $\mathrm{CO}_{2}$ selectivity of this material is a result of tuning pore size and interaction energy for allowing favorable, yet reversible, physical adsorption-desorption of $\mathrm{CO}_{2}$ from ultra dilute $\mathrm{CO}_{2}$ concentration sources such as air. The SIFSIX-3-Cu structure was able to adsorb $1.24 \mathrm{mmol}$ of $\mathrm{CO}_{2}$ per gram of adsorbent at 0.4 mbar over four cycles at a relative humidity of $74 \%$, demonstrating excellent selectivity of $\mathrm{CO}_{2}$ vs $\mathrm{H}_{2} \mathrm{O}$, offering the possibility to capture $\mathrm{CO}_{2}$ over water. However, follow-up reports 
demonstrate that water still poses a problem, even for MOFs of this class, under air capture conditions (Kumar et al., 2015).

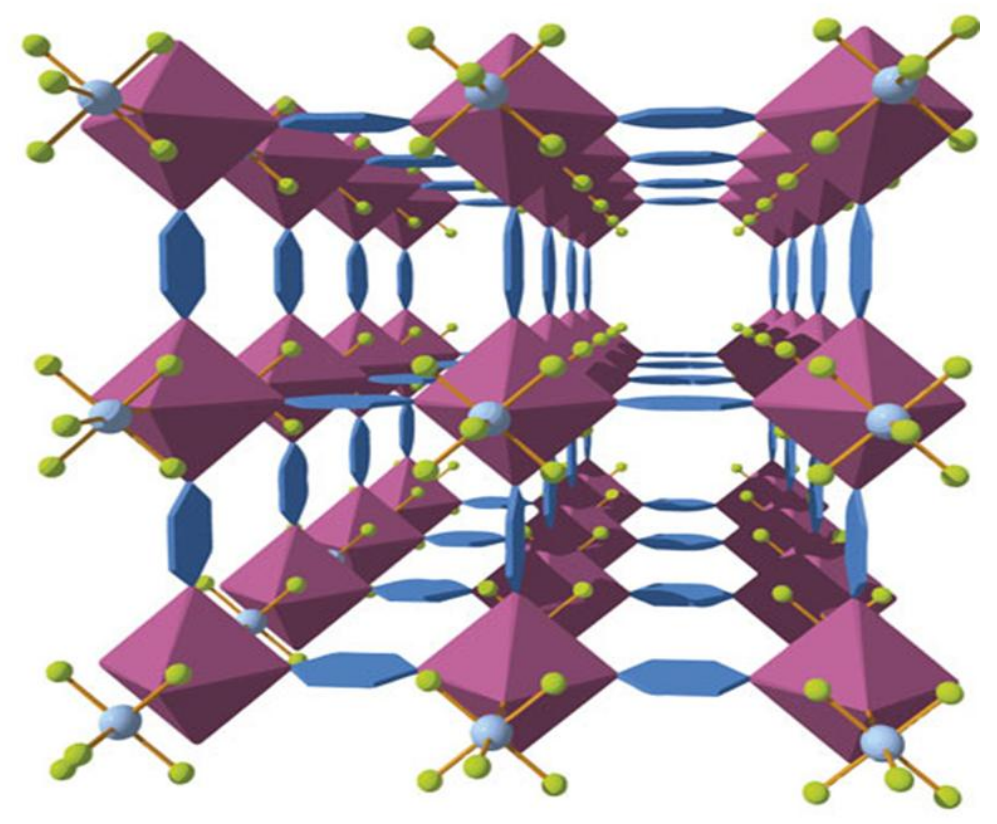

SIFSIX-3-Cu

Figure 6. Pore size tuning of the channel structures of SIFSIX-3-Cu. Color code: pyrazine(blue polygon), $\mathrm{Cu}$ (purple polyhedra). Si (light blue spheres), F (light green spheres).

Reprinted (adapted) by permission from Macmillan Publishers Ltd: [Shekhah, O. et al. Nat. Commun. 2014, 5, 4228-4334.] copyright (2014).

Judicious design of MOFs with controlled pore size and functionalizaion, coupled with inorganic-organic substitution strategies, has the potential to create new materials capable of removing $\mathrm{CO}_{2}$ via direct air capture. This is one area where compuational modeling and simulation can aid in the guided design and stability analysis (mechanical, thermal and chemical) of new $\mathrm{CO}_{2}$ selective MOFs (Walton and Sholl, 2015; Burtch and Walton, 2015; Nie et al. 2015). 


\subsection{Microporous Organic Polymers (MOPs)}

Similar to zeolites and MOFs, microporous organic polymers (MOPs) are porous materials with an average pore size less than $2 \mathrm{~nm}$. However they are composed of light, non-metallic elements such as carbon, hydrogen, oxygen, nitrogen and boron (Jiang and Cooper, 2010). MOPs have ultra-high surface areas, with (to our knowledge) the highest surface area reported for a MOP being $6460 \mathrm{~m}^{2} \mathrm{~g}^{-1}$, made of a polyphenylene structure, PPN-4 (Yuan et al. 2011). A recent review by Dawson et al. highlights various types and functionalized MOPs for selective $\mathrm{CO}_{2}$ sorption over a range of different temperatures and pressures (Dawson et al., 2013). Ultra-high surface area MOPs such as PPN-4 are excellent $\mathrm{CO}_{2}$ scavengers at elevated pressures (total $\mathrm{CO}_{2}$ uptake: $48.20 \mathrm{mmol} / \mathrm{g}$ at $295 \mathrm{~K}$ and $50 \mathrm{bar}$ ) (Yuan et al., 2011; Dawson et al., 2013). Introduction of functional groups into the MOP framework have recently been identified as an efficient and potential strategy to greatly enhance the $\mathrm{CO}_{2}$ uptake of MOPs at atmospheric pressure. This has been mainly attributed to the polarizability and large quadrupole moment of $\mathrm{CO}_{2}$, which can be exploited by introducing $\mathrm{CO}_{2}$-philic functional groups. This create strong interactions between $\mathrm{CO}_{2}$ and the material's surface. Ideal adsorption solution theory (IAST), developed by Myers and Prausnitz (Myers and Prausnitz, 1965), is frequently used to evaluate the ability of a porous material to selectively adsorb $\mathrm{CO}_{2}$ with respect to a mixture of gases (Krishna et al. 2002; Krishna and van Baten, 2011). This method recently reported a mixed component isotherm for an amine grafted porous polymer network, PPN-6- $\mathrm{CH}_{2}$ DETA that can achieve a very high $\mathrm{CO}_{2}$ selectivity and a loading capacity of $1.04 \mathrm{mmol} / \mathrm{g}$ by capturing $\mathrm{CO}_{2}$ directly from air (Figure 7) (Lu et al., 2013). Moreover, a hypothetical regeneration process can be carried out at $98{ }^{\circ} \mathrm{C}$ and the purity of $\mathrm{CO}_{2}$ after separation can approach $99.99 \%$ (Lu et al., 2013). 


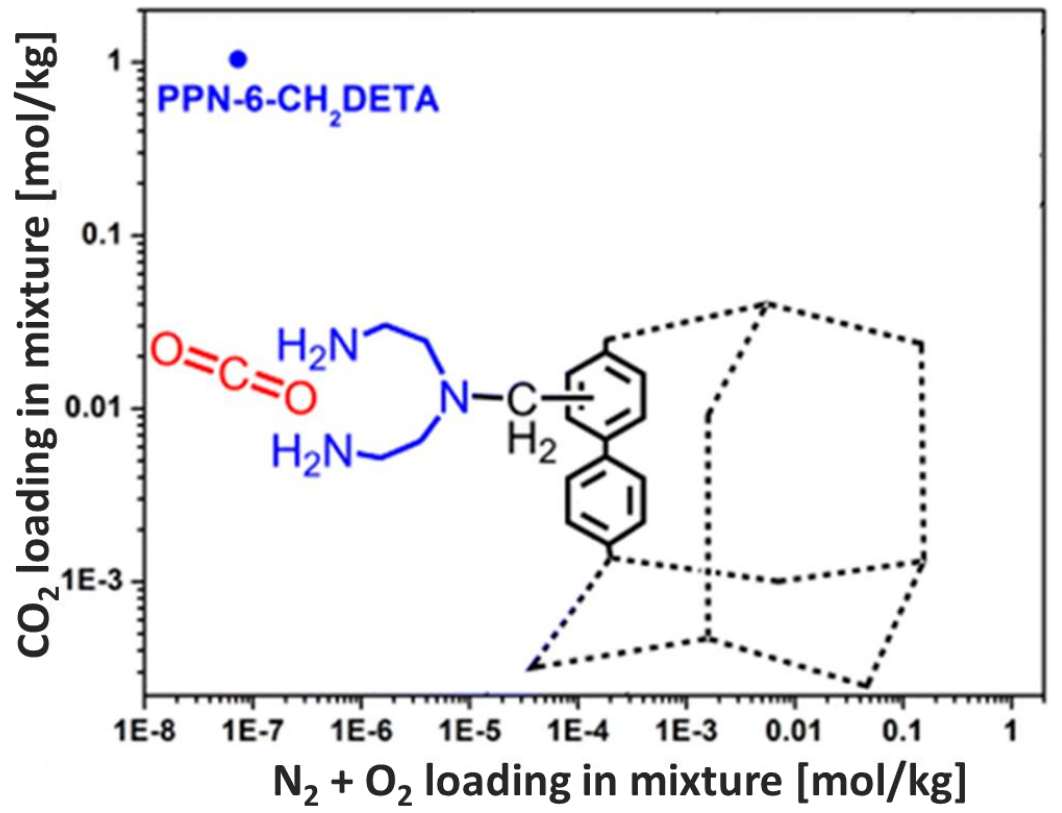

Figure 7. Amine-grafted PPN-6- $\mathrm{CH}_{2} \mathrm{DETA}$ showing high $\mathrm{CO}_{2}$ selectivity $\left(3.6 \times 10^{10}\right)$ and loading capacity $(1.04 \mathrm{~mol} / \mathrm{Kg})$ for capturing $\mathrm{CO}_{2}$ directly from air $\left(400 \mathrm{ppm} \mathrm{CO}_{2}, 78.96 \% \mathrm{~N}_{2}\right.$, and $21 \% \mathrm{O}_{2}$ ) as investigated using IAST.

Reprinted (adapted) with permission from Lu, W. et al. J. Phys. Chem. C 2013, 117, 4057-4061. Copyright (2013) American Chemical Society.

To date, relatively little effort has been devoted to computational analysis of improved MOP structures for cabon capture. Therefore, combining the strengths of molecular simulation methods with synthetic techniques offers exciting opportunities for scientists to design and create new MOP-based materials for efficiently capturing/separating $\mathrm{CO}_{2}$ directly from air. 


\subsection{Activated Carbon}

\subsubsection{Microporous Carbon}

Activated carbon has high surface areas (typically $>1000 \mathrm{~m}^{2} / \mathrm{g}$ ), low chemical activity, and the ability to adsorb molecules from gas and liquid phases due to its highly developed porosity ranging from micropores $(<2 \mathrm{~nm})$ to mesopores $(2-50 \mathrm{~nm})$ and macropores $(>50 \mathrm{~nm})$ (Rodriguez-Reinoso, 2006; Sun et al. 2015). In activated carbon, more than $90 \%$ of the adsorption occurs in the micropores; however meso- and macropores aid the overall performance of the material, because they provide facile pathways to the molecules absorbed into the micropores (Rodriguez-Reinoso, 2006; Sun et al. 2015). Recent reports have shown that narrow microporosity $(<0.7 \mathrm{~nm})$ is the key factor for adsorbing $\mathrm{CO}_{2}$ at low pressures $(\sim 1$ bar $)$ and suggest that adsorption occurs via a "pore-filling" mechanism (Martin et al., 2011; Sun et al. 2013). Carbon based adsorbents for $\mathrm{CO}_{2}$ capture are attractive due to their low cost, fast kinetics, ultra-high stability, ease of regeneration, hydrophobicity, and adsorption capacities at elevated (partial) pressures that are appropriate for $\mathrm{CO}_{2}$ capture and separation from power plant sources (Sun et al., 2015; Choi et al. 2009; Shafeeyan et al., 2011). However, the ability to capture $\mathrm{CO}_{2}$ directly from the atmosphere require more selective and higher $\mathrm{CO}_{2}$ binding affinities. Recent studies have reported several effective strategies to enhance the low pressure $\mathrm{CO}_{2}$ binding affinities of these materials. For example, using polymers as precursors has been identified as a useful technique to generate task-oriented carbon-based sorbents with targeted properties such as purity, porosity, and surface chemistry (Sun et al., 2015). Furthermore, introducing electrondonating hetero-atoms such as nitrogen via reaction with ammonia, nitric acid and amines, (Przepiorski et al., 2004; Zhong et al., 2012; Nandi et al., 2012; Zhao et al., 2012) or sulfur into the carbon framework (Seema et al., 2014) has also been suggested to enhance the $\mathrm{CO}_{2}$ 
adsorption capacities for these materials. Nitrogen containing functional groups, such as amide, imide, lactam, pyrrolic, and pyridinic groups increase the basic character of activated carbon, and enhance the interaction between $\mathrm{CO}_{2}$ and the surface via dipole-dipole, hydrogen, and covalent bonding. High temperature treatment of activated carbon (with surface area $<900 \mathrm{~m}^{2} / \mathrm{g}$ ) with ammonia has been suggested as a potential method to increase $\mathrm{CO}_{2}$ capture by about $25 \%$ (Shafeeyan et al., 2011; Przepiorski et al., 2004). However, a recent report also suggests that presence of up to $\sim 3 \mathrm{wt} \%$ of $\mathrm{N}$ heteroatoms as functional groups in the structure of microporous carbons obtained from pyrrole/pyridone, pyridine, quaternary amines, and pyridine-N-oxide did not significantly improve the $\mathrm{CO}_{2}$ adsorption, with pore size again being the most important factor controlling $\mathrm{CO}_{2}$ sorption. The adsorption proceeded through volume-filling mechanism on micropores with diameter $\sim 0.7-0.8 \mathrm{~nm}$ for $\mathrm{N}$-functionalized material whereas on nonfunctionalized material, the $\mathrm{CO}_{2}$ adsorption proceeded on micropores with diameter smaller than $0.8 \mathrm{~nm}\left(0-25^{\circ} \mathrm{C}, \sim 0-1\right.$ bar of $\left.\mathrm{CO}_{2}\right)$ (Sevilla et al., 2013). An independent report by Mokaya et al. showed that presence of nitrogen had no beneficial effects on $\mathrm{CO}_{2}$ adsorption and minute differences are related to the change in pore size distribution (Adeniran and Mokaya, 2016). It is interesting to note that modified pyrrole molecules assembled with pluronic template via hydrogen bonding and carbonization at low temperatures demostrate high (124:1) specificity of $\mathrm{CO}_{2}$ to $\mathrm{N}_{2}$ adsorption for materials with $\mathrm{N}$-content of 6-8 wt. \%. The observed $\mathrm{CO}_{2}$ adsorption specificity is a result of large fraction of ultra small $(0.5 \mathrm{~nm})$ pores with preserved nitrogen functionality (To et al., 2016). Recently, Ludwinowich et al. studied the effect of adding surfaceactive chemicals and measured the $\mathrm{CO}_{2}$ adsorbing ability of microporous carbon obtained from polymer-based precursors (Ludwinowicz et al., 2015). This study showed that addition of chemical activators to microporous carbon materials improve $\mathrm{CO}_{2}$ adsorption in the following 
order $\mathrm{ZnCl}_{2}<\mathrm{H}_{2} \mathrm{O}<\mathrm{NH}_{3}<\mathrm{CO}_{2}<\mathrm{KOH}$. High volume pores with a diameter $<1 \mathrm{~nm}$ can be achieved by pre-treating carbon with $\mathrm{KOH}$ and results in $\mathrm{CO}_{2}$ uptake of $0.304 \mathrm{~g} \mathrm{CO}_{2} / \mathrm{g}$ of carbon $\left(6.9 \mathrm{mmol} / \mathrm{g}\right.$ at $0{ }^{\circ} \mathrm{C}$ and $\left.1 \mathrm{bar}\right)$.

\subsubsection{Carbon Nanomaterials}

High volume pores with a diameter $<1 \mathrm{~nm}$ can be achieved by pre-treating carbon with $\mathrm{KOH}$ and results in a $\mathrm{CO}_{2}$ uptake of $0.304 \mathrm{~g} \mathrm{CO}_{2} / \mathrm{g}$ of carbon $\left(6.9 \mathrm{mmol} / \mathrm{g}\right.$ at $0{ }^{\circ} \mathrm{C}$ and 1 bar). Carbon nanomaterials including graphene, carbon nanotubes (rolled up sheet of graphene in the form of a tube) and nanohorns (horn-shaped rolled graphene sheets) also present a promising altrernative to activated carbon because their size is in the nanometer range (suggested to be optimal for $\mathrm{CO}_{2}$ capture) (Chandrakumar et al., 2013).

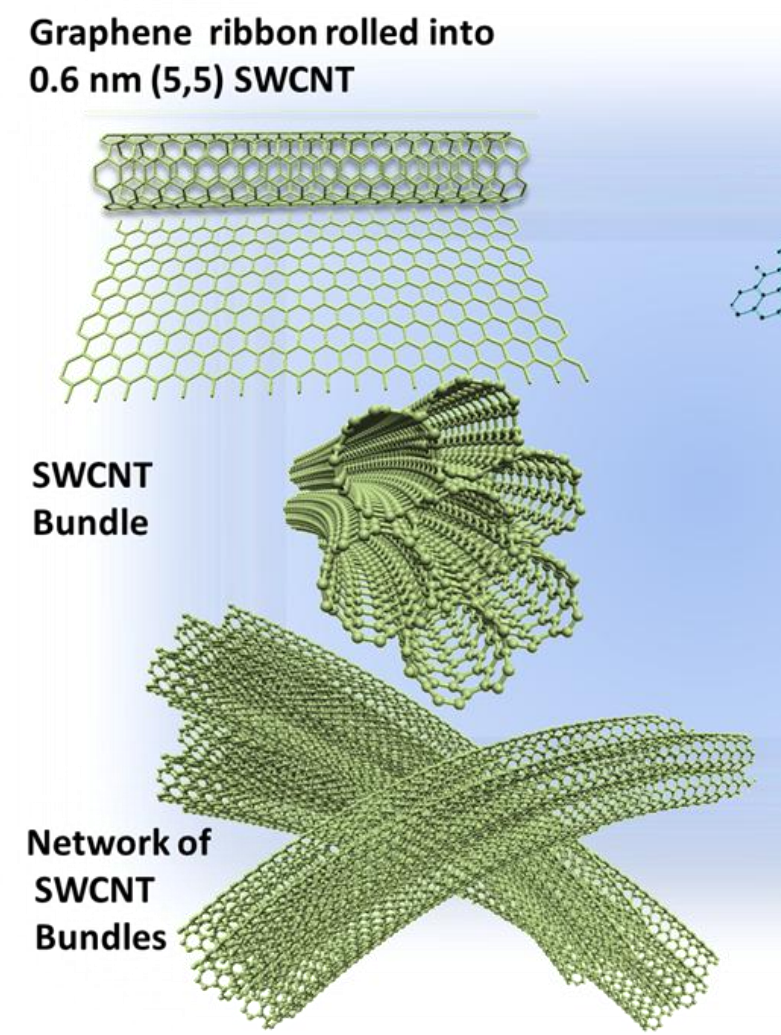

\section{Graphene sheet rolled into} carbon nanohorn
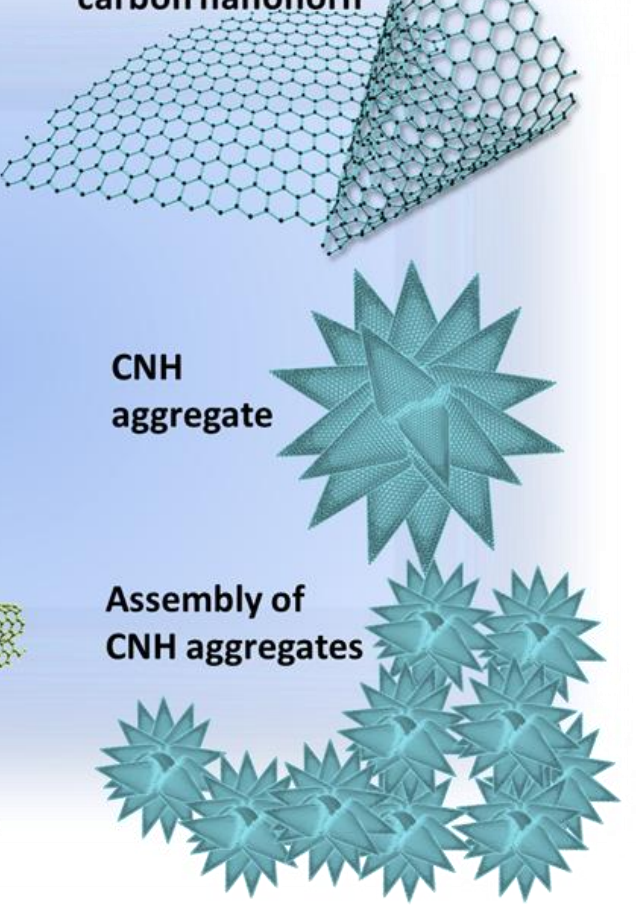
Figure 8. Multi-scale morphology of carbon nanotubes and carbon nanohorns for $\mathrm{CO}_{2}$ capture. CNT morphologies: a bundle of SWNT intercolating network ( 2nm diameter) of carbon nanotubes generated from intersection of micron long bundles are shown for $(5,5)$ SWNT. CNH morphologies: an assembly of carbon nanohorn spherical aggregate formed by multilayer-carbon nanoaggregates. Also shown the graphene sheet cut-out for making $0.6 \mathrm{~nm}(5,5) \mathrm{SWNT}$ and carbon nanohorn $\left(240^{\circ}\right.$ disclination angle, $3 \mathrm{~nm}$ long)

Typical multi-scale structures of interconnected networks of single wall carbon nanotube(SWCNT) bundles and single wall carbon nanohorn (SWCNH) aggregates are shown in Figure 8 along with a graphene sheet cut-out for making a single $(5,5)$ SWNT and $240^{\circ}$ disclination angle SWCNH (Puretzky et al., 2008). Iijima's group recently reported on the thermodynamics of $\mathrm{CO}_{2}$ adsorption on carbon nanohorns (Krungleviciute et al., 2012; Krungleviciute et al., 2013). It was found that unlike other adsorbates $\left(\mathrm{N}_{2} \& \mathrm{CH}_{4}\right), \mathrm{CO}_{2}$ is not strongly attracted to the surface of graphene and adsorption is dominated by stronger gas-gas interactions for $\mathrm{CO}_{2}$. This is due to the large quadrupole moment of $\mathrm{CO}_{2}$ molecules, resulting in

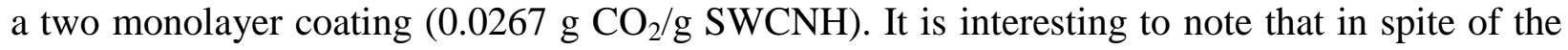
different nature of SWCNH and SWCNT, they show similar $\mathrm{CO}_{2}$ adsorption charateristics, akin to graphite where strong quadrupole interactions between $\mathrm{CO}_{2}$ molecules lead to hysterestis on adsorption curves (Bienfait et al., 2004; Terlain and Larher, 1983). On SWCNT bundles, the $\mathrm{CO}_{2}$ coverage was found to be $0.8 \mathrm{mmol} / \mathrm{g}\left(0.352 \mathrm{~g} \mathrm{CO}_{2} / \mathrm{g}\right.$ of $1.7 \mathrm{~nm}$ diameter SWCNT) at $130 \mathrm{~K}$ with an isosteric heat of adsorption close to that for the basal plane of graphite, about $22.5 \mathrm{~kJ} / \mathrm{mol}$ (Bienfait et al. 2004). The adsorbed layer of $\mathrm{CO}_{2}$ is stablized due to entropic effects in the grooves and in the interstitial channels in the SWCNT bundle. For hydroxylated poly(ethyleneimine) modifed 3D-porous graphene scaffolds, the largest $\mathrm{CO}_{2}$ uptake was found to be around $4.13 \mathrm{mmol} / \mathrm{g}\left(0.181 \mathrm{~g} \mathrm{CO}_{2} / \mathrm{g}\right.$ of carbon $)$ measured in simulated ambient air under 1 atm of dry $\mathrm{CO}_{2}$ for the sample with an averaged pore size of $15 \mathrm{~nm}$ (Liu et al. 2015). 


\subsubsection{Hetero-atom Activated Carbon}

In the context of hetero-atom activated carbon, an analogous class of structurally similar materials is boron nitride nanomaterials $(\mathrm{BN})$. However, in boron nitride nanomaterials, which include nanosheets and nanotubes (BNNT), nitrogen is a primary part of the material structure, whereas in carbon based nanomaterials, it is typically a low concentration dopant. Due to the difference in electronegativity between $\mathrm{B}$ (2.04) and $\mathrm{N}$ (3.04) atoms, the electrons on $\mathrm{BN}$ nanomaterials are not delocalized, leading to asymmetric charge distribution. Recent first principles density-function theory calculations showed that if the surface of a BN nanomaterial is negatively charged, the $\mathrm{CO}_{2}$ could be physically or chemically adsorbed on the surface (adsorption energy $\sim 67 \mathrm{~kJ} / \mathrm{mol}$ ). The highest adsorption energy is expected for a $\mathrm{BN}$ nanosheet $(70 \mathrm{kcal} / \mathrm{mol})$ and BNNT $(77 \mathrm{kcal} / \mathrm{mol})$ with $(5,5)$ unit cell symmetry, which have a charge density equivalent to two electrons (Sun et al., 2013). Reduction of BNNT (negative charging of nanotubes) increases their reactivity towards reaction with $\mathrm{NH}_{2}$ radicals by a factor of five compared to neutral nanotubes (Shin et al. 2015). Unlocking reactivity of reduced BNNTs could provide a pathway for development of hybrid coatings to improve $\mathrm{CO}_{2}$ capture. A concept of electrocatalytically switchable $\mathrm{CO}_{2}$ capture on graphitic carbon nitride $\left(\mathrm{g}-\mathrm{C}_{4} \mathrm{~N}_{3}\right)$ was modeled using first principles calculations for negatively charging surfaces with one and two electrons (Tan et al., 2015). Negative charging of $\mathrm{g}-\mathrm{C}_{4} \mathrm{~N}_{3}$ can lead to significant enhancement of $\mathrm{CO}_{2}$ capturing ability with estimated $\mathrm{CO}_{2}$ capture capacity up to $42.3 \mathrm{wt} . \%$, and adsorption energy of about $88 \mathrm{kcal} / \mathrm{mol}$ (Tan et al., 2015). Previously it was shown through ab initio calculations that $\mathrm{CO}_{2}$ chemisorption in boron-rich BNNT is almost independent of the tube diameter (Choi et al., 2011a). Design of carbon-based and similar nanomaterials adsorbents with high surface area, small pore size, and surface modification enabling high selectivity for capturing $\mathrm{CO}_{2}$ from a 
dilute gas mixture at various humidity levels remains challenging. However, recent results for designing new hierarchically-structured carbon adsorbates or analogous materials suggest that breakthroughs might be possible for this class of adsorbents in the near future.

\subsection{Supported Amine-Sorbents}

Many of the materials discussed above that offer both high $\mathrm{CO}_{2}$ capacities and tolerance to humidity contain amines as the key $\mathrm{CO}_{2}$ binding sites. The presence of highly basic amine groups on the surface of the supported systems results in a strong affinity for binding with $\mathrm{CO}_{2}$. Moreover, the ability of these materials to operate at near ambient conditions, their tolerance to humidity, and mild temperature regeneration make them attractive as air capturing sorbents (Choi et al., 2009; Didas et al., 2015; Choi et al., 2011b). Moreover, Prakash and co-workers recently reported the use of a polyamine; pentaethylenehexamine (PEHA), for directly converting $\mathrm{CO}_{2}$ from air into methanol (Kothandaraman et al., 2016). In this work, they demonstrated that by using PEHA and a ruthenium-based homogeneous catalyst, $79 \%$ of $\mathrm{CO}_{2}$ captured directly from air was converted into methanol. Conversion of atmospheric $\mathrm{CO}_{2}$ to methanol using amines is highly significant because of methanol's potential use as an alternative fuel in fuel cells and hydrogen storage (Carbon dioxide captured from air can be directly converted into methanol fuel, 2016). Supported amine-adsorbents based on primary, secondary, or tertiary amines are one of the most developed and promising classes of materials for directly capturing $\mathrm{CO}_{2}$ from air (Didas et al., 2015). Compared to MOFs and MOPs, the preperation of traditional supported amine-adsorbents based on porous oxide supports functionalized with amines is simple and relatively inexpensive (Didas et al., 2015). Supported amine adsorbents have been previously classified into three types based on their synthesis: Class 1 adsorbents consist of polymeric or oxide supports (typically silica) that are physically loaded with amine- 
containing small molecules or polymers. Class 2 adsorbents contain amine moieties (small molecules) covalently bonded to a solid support; and class 3 adsorbents are comprised of a solid support covalently bonded to polymeric amines prepared by in situ polymerization of the support surface, resulting in a large number of active $\mathrm{CO}_{2}$ capturing sites on the surface (Jones et al., 2011; Goeppert et al., 2012; Choi et al., 2009; Choi et al., 2011b; Bollini et al., 2011). Among class 1 adsorbents, poly(ethyleneimine) (PEI) -based sorbents typically show the highest capacity for capturing $\mathrm{CO}_{2}$ directly from air (Goeppert et al., 2012; Goeppert et al., 2011; Chaikittisilp et al., 2011). Class 1 adsorbents are easy to prepare and show excellent ability to adsorb $\mathrm{CO}_{2}$ directly from air; however, due to the lack of chemical bonds between the support and the active adsorbent, these materials can sometimes undergo leaching and instability during regeneration (Goeppert et al., 2010). Class 2 type supported amine sorbents are more stable and were first reported for direct air capture by Belmabkhout et al (Belmabkhout et al., 2010). Poreexpanded mesoporous silica (PE-MCM-41) was functionalized with 3-[2-(2aminoethylamino)ethylamino]propyltrimethoxysilane (TRI) and the functionalized material (TRI-PE-MCM-41) showed high adsorption capacity $(0.98 \mathrm{mmol} / \mathrm{g})$ at low $\mathrm{CO}_{2}$ concentrations $(400 \mathrm{ppm})$ at $25 \quad{ }^{\circ} \mathrm{C}$. Wurzbacher et al. grafted [N-(2-Aminoethyl)-3aminopropyl]trimethoxysilane (AEAPTMS) onto silica gel beads, and reported extracting $\mathrm{CO}_{2}$ from dry and humid air at $97 \%$ purity using a combination of pressure and temperature swing adsorption methods (Goeppert et al., 2012; Wurzbacher et al. 2011). The adsorbent showed good stability over 40 consecutive adsorption/desorption cycles with a $\mathrm{CO}_{2}$ capture capacity of 2 $\mathrm{mmol} / \mathrm{g}$ per cycle. The development of class 3 adsorbents was based on combining the high nitrogen loading present in class 1 adsorbents, with the high stablity and low volatility of class 2 absorbents (Figure 9) (Choi et al., 2012; Didas et al., 2015; Choi et al., 2011b; Choi et al., 
2011c). A recent report using a class 3 absorbent based on a hyperbranced aminosilica (HAS) shows $\mathrm{CO}_{2}$ capture capacity from ultra dilute sources such as ambient air to be about $1.7 \mathrm{~mol}$ $\mathrm{CO}_{2} / \mathrm{kg}$ sorbent for the highest amine containing material; $42 \mathrm{wt} \%$ aminopolymer (Didas et al., 2015).

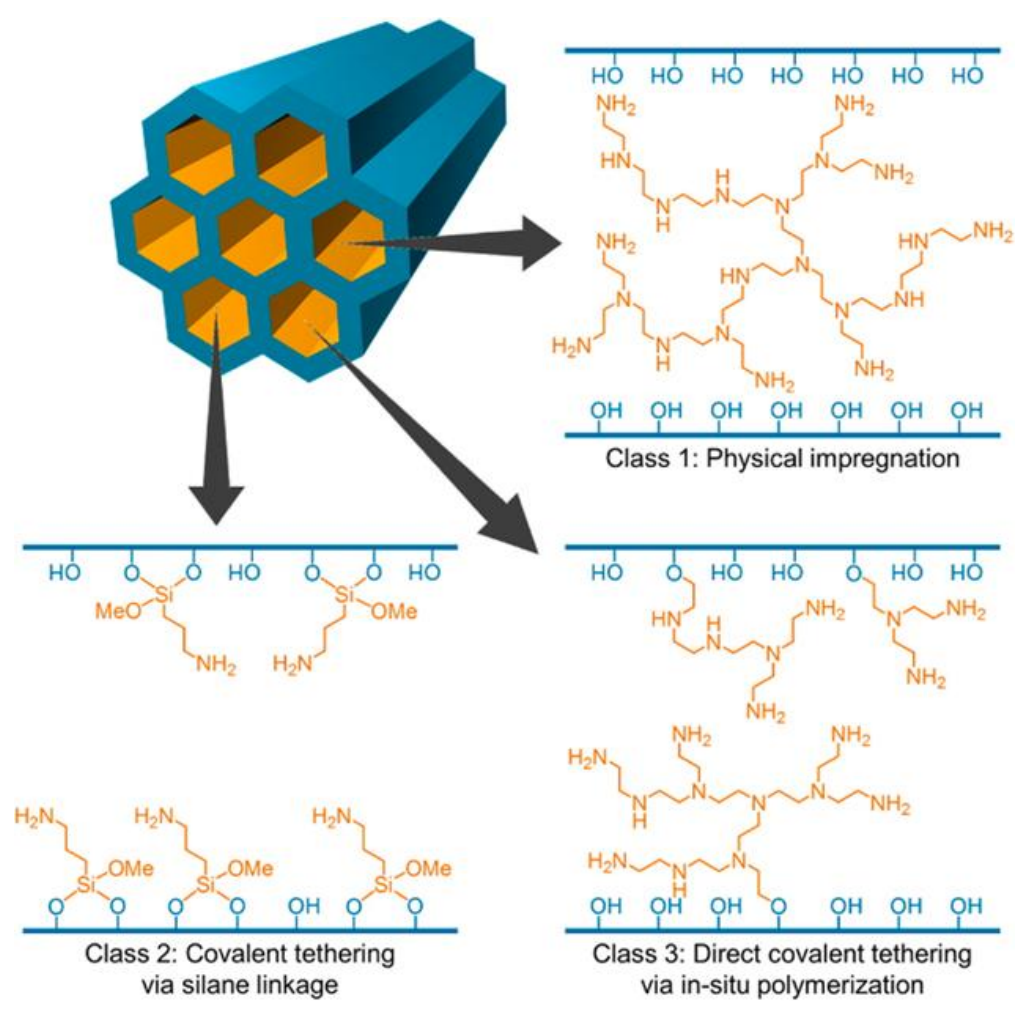

Figure 9. Representation of the three classes of amine adsorbent materials.

Reprinted (adapted) with permission from Didas, S. A. et al. Acc. Chem. Res. 2015, 48, 2680-2687. Copyright (2015) American Chemical Society.

Jones et al. detailed the design of class 3 type HAS sorbents via surface immobilization of polymeric chemisorbents via ring-opening polymerization of aziridine over mesoporous silica (Choi et al., 2012; Didas et al., 2015; Choi et al., 2011b; Choi et al., 2011c). However, higher amine-containing Class 3 materials have slower adsorption kinetics due the blocking of pores, 
which hinders $\mathrm{CO}_{2}$ diffusion within these materials (Didas et al., 2015). In addition to HAS-type sorbents, another strategy that has been reported that uses an aminopropyl-functionalized mesoporous silica support, to polymerize Z-protected $\mathrm{L}_{\mathrm{L}}$-lysine $\mathrm{N}$-carboxyanhydride (Lunn and Shantz, 2009; Chaikittisilp et al., 2011). In a related approach, Qi et al. prepared linear polyamines grafted to a porous silica sponge that displayed exceptionally high $\mathrm{CO}_{2}$ sorption capacities (Qi and Giannelis, 2014). These supported-amine sorbents are advantageous because they can be regenerated at temperatures between $70-120{ }^{\circ} \mathrm{C}$ or lower if vacuum is applied (Wurzbacher et al., 2011; Serna-Guerrero, 2010). However, for the practical appliction of these materials, the long-term stability will also need to be considered. Currently, two modes of degradation have been identified for these materials ( $\mathrm{Li}$ et al., 2010a; Li et al., 2010b; HeydariGorji, et al., 2012; Sayari et al., 2012; Gebald et al., 2013). The first mode of degradation involves amine oxidation, with primary amines being the most stable under oxidation and other expected conditions (Didas et al., 2012; Bollini et al., 2011; Calleja et al., 2011; Heydari-Gorji et al., 2011). The second mode involves degradation of the support system. A loss of porosity was reported for amines supported on highly porous, thin-walled silica upon exposure to steam conditions (Serna-Guerrero et al., 2010). Recent reports have shown that amine-supported basic alumina materials are a more stable $\mathrm{CO}_{2}$ sorbent than conventional silica-supported materials under silimar conditions (Bali et al. 2014). However, commercially available alumina supports have lower porosity than their silica counterparts, requiring a balance between stability and active amine-content when steaming is used for desorption (Didas et al., 2015). High porosity, steam-stable sorbents could have some advantages (Wilfong et al., 2015).

Supported amine-sorbents, which are related to MOFs, carbons, zeolites, etc., can be viewed as one of the most developed "air-capturing" agents. Nonetheless, the development of practical 
adsorbents for direct air capture applications is still in its infancy. The practical applicability of these materials will be determined by their $\mathrm{CO}_{2}$ capture/release efficiency, long-term stability under the process conditions and the overall cost and safety of the deployed system. To this end, there are still many fundamental research challenges that must be overcome to fully optimize and evaluate these materials for direct air capture. The $\mathrm{CO}_{2}$ adsorption properties of supported amino-polymers have been linked to morphological and dynamical characteristics of the polymeric phase, but are not fully characterized. Utilization of modeling and simulation approaches can help bridge this gap in terms of providing a fundamental understanding of the structural and dynamic properties of these systems, which in turn can be used to design systems with enhanced carbon capture capabilities (Barkakaty et al., 2016; Carrillo et al., 2015; Holewinski et al., 2015). We also note that compared to alkylamine-based sorbents discussed here, other nitrogen-containing basic moieties such as amidines that typically have higher basicities than amines (Alkhabbaz et al., 2014) are under-explored and might offer potential as more efficient materials for capturing $\mathrm{CO}_{2}$ directly from air (Endo et al., 2004). For example, Heldebrant and coworkers reported the use of amidine/guanidine based structures as the first examples of $\mathrm{CO}_{2}$-responsive solvents that could capture $\mathrm{CO}_{2}$ directly from air (Heldebrant et al., 2008). Recently, Furusho et al. has shown that polymers containing amidine groups have higher $\mathrm{CO}_{2}$ fixing efficiencies than PEIs (Furusho and Endo, 2013), which are reported to have the highest capacities to capture $\mathrm{CO}_{2}$ directly from air among all the to-date studied amines (Goeppert et al., 2012; Goeppert et al., 2011; Chaikittisilp et al., 2011). However, unlike the synthesis for amine-based polymers, synthesis of amidine-based polymers is a cumbersome process. Recently, a facile synthesis of amidine-based polymers by post-polymer modification of poly(2 vinyl-4,4-dimethylazlactone) (PVDMA) has been reported (Barkakaty et al., 2016). To 
the best of our knowledge, the PVDMA functionalized polymer has a higher selectivity, and $\mathrm{CO}_{2}$ fixing efficiency, than previously reported polymers (Furusho and Endo, 2013) including PEI and aliphatic poly(amidine) (Barkakaty et al., 2016). Thus like amines (Kothandaraman et al., 2016; Carbon dioxide captured from air can be directly converted into methanol fuel, 2016), amidines (Barkakaty et al., 2010; Barkakaty et al., 2011) are also interesting candidates to explore as carbon capture materials because the captured $\mathrm{CO}_{2}$ can be utilized for in situ chemical transformation into compounds that can be used as building blocks for producing high-utility products. Therefore development of novel base supported systems with higher $\mathrm{CO}_{2}$ uptake/release efficiencies, longer shelf-lifes and better scope for reducing the cost of carbon capture with efficient in situ utilization of $\mathrm{CO}_{2}$ as a chemical feedstock, holds promise for potential direct air capture $\mathrm{CO}_{2}$ utilization technology.

\section{Outlook and Conclusions}

Practical applications of direct air capture has already been successfully implemented in submarines and spacecraft equipped with closed-circuit breathing systems (CCBSs) (Goeppert et al., 2012; Ranjan and Herzog, 2011; Huang et al., 2009; Satyapal, 2001). For example, NASA reported that a poly(methacrylate)-supported PEI/poly(ethyleneglycol) (PEG)-based sorbent was

capable of reversibly capturing and removing $\mathrm{CO}_{2}$, maintaining an acceptable $\mathrm{CO}_{2}$-level in a seven person spacecraft (Goeppert et al., 2012; Huang et al., 2009). However, theororetical calculations suggest that capturing $\mathrm{CO}_{2}$ from air require about 3.4 times more energy than what is needed to capture $\mathrm{CO}_{2}$ from flue gas if the separations were completed in a reversible manner (Ranjan and Herzog, 2011). The extensive adoption of air capture / negative emission technologies will depend on various factors including high sorption capacities, high sorption and desorption kinetics, high selectivity, long-term stability, flexibility, high surface areas, ease of 
synthesis, scalability, and cost. Inorganic strong bases such as $\mathrm{NaOH}, \mathrm{KOH}$ and $\mathrm{Ca}(\mathrm{OH})_{2}$ show high capacities for capturing $\mathrm{CO}_{2}$ from air but suffer from high energy penalties for regenaration. Most of the zeolites and MOFs are sensitive to moisture and hence not suitable candidates for direct air capture. However, recent studies in MOFs and activated carbon based materials indicate that strategic methods to control the pore size distribution with suitable functionalization are key factors for designing new materials in this category. For MOPs, functionalization with strong $\mathrm{CO}_{2}$-philic functional groups such as amines have been identified as a potential strategy to enhance the ability of these materials for direct air capture.

Incorporation of sorbents that operate by unique mechanisms may also offer new ways of achieving cost effective DAC. As an example, a moisture-swing sorption process developed by Lackner et al. for capturing $\mathrm{CO}_{2}$ from ambient air using anionic exchange resins is a method that relies on a different, possibly hybrid ad/absorption mechanism for DAC. In this method, the sorbent binds $\mathrm{CO}_{2}$ under (relatively) dry conditions and releases it when hydrated. This method is correlated with changes in the hydration energies of the resin surface and therefore the sorption/release of $\mathrm{CO}_{2}$ can be predicted and controlled as a function of humidity and temperature (Wang et al., 2013). Recent work on the improvement of adsorption kinetics showed that reducing the size of the sorbent particles can substantially improve the rate of ad/absorption under lower temperature conditions (Wang et al., 2016). In another example, a recent report of a new class of functional porous materials that combines the fluidity of a liquid with permanent porosity of porous solids might have potential application for directly capturing $\mathrm{CO}_{2}$ from air (Giri et al., 2015). These materials consist of cage molecules, having well-defined pore size, and are highly soluble in solvents with molecular sizes that are larger than the size of its pores thereby prohibiting the solvent molecules to penetrate into its molecular cage. These materials 
combine the benefits of free-flowing liquids used in conventional flow process for carbon capture and lower energy requirements for adsorption-release cycles in solid well-defined porous adsorbents. Boron-nitride nanomaterials are another class of porous materials that offers potential opportunities for developing novel materials for future applications in air capture technologies.

To date, supported amine-adsorbents are one of the most developed and promising materials for air capture technologies. These materials demonstrate high $\mathrm{CO}_{2}$ capturing efficiency, tolerance to moisture and mild temperature regeneration. Moreover, a recent report on application of a polyamine for directly converting $\mathrm{CO}_{2}$ captured from air into methanol emphasizes the potential of these materials for enabling the use of atmospheric carbon as a source of alternative fuels in the future (Kothandaraman et al., 2016; Carbon dioxide captured from air can be directly converted into methanol fuel, 2016). However, the current state of art for these materials suggests that further $\mathrm{R} \& \mathrm{D}$ is needed to improve their long-term stability for practical applications. The development of novel solid immobilized funtional groups such as amidines having higher stability and basicity than amines and the ability for utilization of the captured $\mathrm{CO}_{2}$ as chemical feedstock may lead to the next breakthrough in this field. In the search for new breakthroughs, computation and molecular simulation are expected to play an important role in guiding experimental scientists in designing new materials with optimized structures for increased efficiency and stability to capture $\mathrm{CO}_{2}$ directly from air.

The materials disccused in this article to develop carbon negative technologies are synthetic materials that employ chemical processes to capture $\mathrm{CO}_{2}$ directly from air. Another noteworthy class of carbon negative materials that has gained significant attention is biochar. Biochar is a carbon-enriched solid material obtained by removing all of the volatile hydrocarbons and most of 
the oxygen and hydrogen content in a biomass via heating in the absence or presence of a limited supply of oxygen (Tenebaum, 2009). Biochar materials have the potential to be carbon negative because of their ability to resist chemical and microbial degradation when deployed as a carbon storage medium, retaining a substantial portion of carbon fixed by plants through photosynthesis. Unlike ordinary biomass that adds carbon to the atmosphere via the natural process of biodegradation, biochar stores carbon in a more stable form. Global implementation combining biochar production and its storage in soil could have the potential to avoid net $\mathrm{CO}_{2}$ emissions on the order of $1.8 \mathrm{Pg}(1 \mathrm{Pg}=1 \mathrm{Gt}) \mathrm{CO}_{2}-\mathrm{C}$ equivalent $\left(\mathrm{CO}_{2}-\mathrm{C}_{\mathrm{e}}\right)$ annually, and of $130 \mathrm{Pg} \mathrm{CO}_{2}-\mathrm{C}_{\mathrm{e}}$ over the course of a century while preserving biodiversity, ecosystem stability and food security (Woolf et al., 2010).

NASA and the National Oceanic and Atmospheric Administration (NOAA) have reported that 2014 was the Earth's warmest year since 1880 (NASA, NOAA find 2014 warmest in modern record, 2015). Recent reports suggested that 2015 was even warmer (Thomson, 2016). In the recent Paris agreement that was adopted by 195 countries on December 12th, 2015 at the twentyfirst Conference of the United Nations Framework Convention on Climate Change (UNFCC), world leaders agreed to take necessary actions to limit the rise in the average global temperature below $2{ }^{\circ} \mathrm{C}$ by 2100 (Editorial, 2016). Therefore, the development of effective carbon capture technologies will be key to control future atmospheric $\mathrm{CO}_{2}$ levels. Solomon et al. used Atmosphere-Ocean General Circulation Models (AOGCMs) and Earth System Models of Intermediate Complexity (EMICs) and reported that irreversible climate change will occur if the atmospheric $\mathrm{CO}_{2}$ concentration increases from around 385 parts per million (ppm) to 450-600 ppm (Solomon et al., 2009). The current atmospheric $\mathrm{CO}_{2}$ concentration is already very high, 402 ppm (December 2015) (Earth's $\mathrm{CO}_{2}$ Home Page, 2016), and as more than 50\% 
anthropogenic carbon emission comes from distributed sources, point source emission reductions alone will not be able to slow down the effects of global warming without considering additional “carbon negative" strategies such as air capture.

The cost of capturing $\mathrm{CO}_{2}$ directly from air will be the key factor that determines whether negative carbon processes are deployed. However, as highlighted in this work, suitable technologies for capturing $\mathrm{CO}_{2}$ directly from air still require significant research and development (R\&D), and cost estimates of early technologies are often not accurate, as the cost can drop by orders of magnitude with mass production and further developments. Furthermore, a combination of air capture with suitable $\mathrm{CO}_{2}$-conversion technologies will aid in further reducing the cost. Therefore, growth in $\mathrm{R} \& \mathrm{D}$ of new materials for capturing $\mathrm{CO}_{2}$ from ultra-dilute sources coupled with model and computational aided design holds the key for future materials and technology to make "air capture" become economically feasible.

\section{Acknowledgement}

This research was performed at the Center for Nanophase Materials Sciences, which is a Department of Energy (DOE) Office of Science User Facility. BGS, CWJ and MEP acknowledge partial support from the Center for Understanding and Control of Acid GasInduced Evolution of Materials for Energy (UNCAGE-ME), an Energy Frontier Research Center funded by U.S. Department of Energy, Office of Science, Basic Energy Sciences. 


\section{References}

Adeniran, B., Mokaya, R., 2016. Is N-Doping in Porous Carbons Beneficial for $\mathrm{CO}_{2}$ Storage? Experimental Demonstration of the Relative Effects of Pore Size and N-Doping. Chem. Mater. 28, 994-1001.

Alkhabbaz, M. A., Khunsupat, R., Jones, C. W., 2014. Guanidinylated poly(allylamine) supported on mesoporous silica for CO2 capture from flue gas. Fuel 2014, 121, 79-85.

Baciocchi, R., Storti, G., Mazzotti, M. 2006. Process design and energy requirements for the capture of carbon dioxide from air. Chem. Eng. Process 45, 1047-1058.

Bali, S. et al. 2014. Aminosilanes Grafted to Basic Alumina as $\mathrm{CO}_{2}$ Adsorbents-Role of Grafting Conditions on $\mathrm{CO}_{2}$ Adsorption Properties. ChemSusChem 51, 3145-3156.

Barkakaty, B. et al. 2016. Amidine-Functionalized Poly(2-vinyl-4,4-dimethylazlactone) for Selective and Efficient $\mathrm{CO}_{2}$ Fixing. Macromolecules 49, 1523-1531.

Barkakaty, B. et al. 2010. Amidine-mediated delivery of $\mathrm{CO}_{2}$ from gas phase to reaction system for highly efficient synthesis of cyclic carbonates from epoxides. Green Chem. 12, 42-44.

Barkakaty, B. et al. 2011. Synthesis of a methacrylic monomer having pendant cyclohexene cyclic carbonate - easy $\mathrm{CO}_{2}$ fixation and radical polymerization. J. Polym. Sci. A Polym. Chem. 49, 545-549.

Belmabkhout, Y. et al. 2010. Amine-bearing mesoporous silica for $\mathrm{CO}_{2}$ removal from dry and humid air. Chem. Eng. Sci. 65, 3695-3698.

Breck, D. W. 1974. Zeolite Molecular Seives: Structure, Chemistry and Use. New York: John Wiley \& Sons, Inc. 771p.

Bienfait, M. et al. 2004. Thermodynamics and structure of hydrogen, methane, argon, oxygen, and carbon dioxide adsorbed on single-wall carbon nanotube bundles. Phys. Rev. B 70 (035410), $1-10$.

Boden, T. A., Marland, G., Andres, R. J. 2015. Fossil fuel combustion and cement production emissions: Global, Regional, and National Fossil-Fuel $\mathrm{CO}_{2}$ Emissions, Carbon Dioxide Information Analysis Center, Oak Ridge National Laboratory, U.S. Department of Energy, Oak Ridge, Tenn., U.S.A.

Bollini, P., Didas, S. A., Jones, C. W. 2011. Amine-oxide hybrid materials for acid gas separations. J. Mater. Chem. 21, 15100-15120.

Bollini, P. et al. 2011. Oxidative Degradation of Aminosilica Adsorbents Relevant to Postcombustion $\mathrm{CO}_{2}$ Capture. Energy \& Fuels 25, 2416-2425.

Burtch, N. C., Walton, K. S. 2015. Modulating Adsorption and Stability Properties in Pillared Metal-Organic Frameworks: A Model System for Understanding Ligand Effects. Acc. Chem. Res. 48, 2850-2857. 
Calleja, G. et al. 2011. Influence of Drying Conditions on Amine-Functionalized SBA-15 as Adsorbent of $\mathrm{CO}_{2}$. Top. Catal. 54, 135-145.

C. Le Quéré et al. 2015. Global Carbon Budget. Earth Sys. Sci. Data 7, 349-396.

Carbon Engineering. Industrial-Scale Capture of $\mathrm{CO}_{2}$ from Ambient Air. Available Online: http://carbonengineering.com/about-ce/ (accessed on $3^{\text {rd }}$ November 2015).

Carbon dioxide captured from air can be directly converted into methanol fuel. Available online: http://phys.org/news/2016-01-carbon-dioxide-captured-air-methanol.html (accessed 1st February, 2016).

Carrillo, J. M. Y. et al. 2015. Unraveling the Dynamics of Aminopolymer/Silica Composites. Langmuir 32, 2617-2625.

Canadell, J. G. et al. 2007. Contributions to accelerating atmospheric $\mathrm{CO}_{2}$ growth from economic activity, carbon intensity, and efficiency of natural sinks. Proc. Natl. Acd. Sci. U.S.A 104, 18866-18870.

Caskey, S. R., Wong-Foy, A. G, Matzger, A. J. 2008. Dramatic Tuning of Carbon Dioxide Uptake via Metal Substitution in a Coordination Polymer with Cylindrical Pores. J. Am. Chem. Soc. 130, 10870-10871.

Chandrakumar, K. R. S et al. 2013. High-temperature transformation of Fe-decorated singlewall carbon nanohorns to nanooysters: a combined experimental and theoretical study. Nanoscale 5, 1849-1857.

Chaikittisilp, W. et al. 2011. Poly(allylamine)-Mesoporous Silica Composite Materials for $\mathrm{CO}_{2}$ Capture from Simulated Flue Gas or Ambient Air. Ind. Eng. Chem. Res. 2011, 50, 1420314210 .

Chaikittisilp, W. et al. 2011. Poly(L-lysine) Brush-Mesoporous Silica Hybrid Material as a Biomolecule-Based Adsorbent for $\mathrm{CO}_{2}$ Capture from Simulated Flue Gas and Air. Chem.-Eur. J. 17, 10556-10561.

Cheetham, A. K., Rao, C. N. R. 2007. There's Room in the Middle. Science 318, 58-59.

Chen, B. et al. 2001. Interwoven metal-organic framework on a periodic minimal surface with extra-large pores. Science 291, 1021-1023.

Choi, S. et al. 2009. Adsorbent materials for carbon dioxide capture from large anthropogenic point sources. ChemSusChem 2, 796-854.

Choi, H. et al. 2011. Ambient carbon dioxide capture by boron-rich boron nitride nanotube. J. Am. Chem. Soc. 133, 2084-2087.

Choi, S. et al. 2011. Application of amine-tethered solid sorbents for direct $\mathrm{CO}_{2}$ capture from the ambient air. Environ. Sci. Technol. 45, 2420-2427.

Choi, S. et al. 2011. Application of amine-tethered solid sorbents to $\mathrm{CO}_{2}$ fixation from air. US Pat., 2011/0179948A1. 
Choi, S. et al. 2012. Modification of the Mg/DOBDC MOF with Amines to Enhance $\mathrm{CO}_{2}$ Adsorption from Ultradilute Gases. J. Phys. Chem. Lett. 3, 1136-1141.

Damiani, D. L. et al. 2011. The US Department of Energy's R\&D program to reduce greenhouse gas emissions through beneficial uses of carbon dioxide. Greenhouse Gas. Sci. and Technol. 1, $1-11$.

Dawson, R., Cooper, A. I., Adams, D. J. 2013. Chemical functionalization strategies for carbon dioxide capture in microporous organic polymers. Polym. Int. 62, 345-352.

Deem, M. W., Pophale, R., Cheeseman, P. 2011. A database of new zeolite-like materials. Phys. Chem. Chem. Phys. 13, 12407-12412.

Didas, S. A. et al. 2015. Amine-Oxide Hybrid Materials for $\mathrm{CO}_{2}$ Capture from Ambient Air. Acc. Chem. Res. 48, 2680-2687.

Didas, A. et al. 2012. Role of Amine Structure on Carbon Dioxide Adsorption from Ultradilute Gas Streams such as Ambient Air. ChemSusChem 5, 2058-2064.

Direct Air Capture of $\mathrm{CO}_{2}$ with Chemicals, A Technology Assessment for the APS Panel on Public Affairs, 2011. https://www.aps.org/policy/reports/assessments/upload/dac2011.pdf. (accessed on $18^{\text {th }}$ January, 2016).

Eddaoudi, M. et al. 2002. Systematic design of pore size and functionality in isoreticular MOFs and their application in methane storage. Science 295, 469-472.

Endo, T. et al. 2004. A Novel Construction of a Reversible Fixation-Release System of Carbon Dioxide by Amidines and Their Polymers. Macromolecules 37, 2007-2009.

Editorial, 2016. All for less carbon. Nat. Mater. 2016, 15, 113. doi: 10.1038/nmat4562.

Earth's $\mathrm{CO}_{2}$ Home Page. 2016. Available Online: https://www.co2.earth/ (accessed on $1^{\text {st }}$ February, 2016).

Flanigen, E. M. 1991. Zeolites and Molecular Seives. An historical perspective. In: van Bekkum H., Flanigen, E. M., Jansen, J. C., editors. Introduction to Zeolite Science and Practice. Amsterdam: Elsevier Science Publishers B. V. p 13-34.

Furusho, Y., Endo, T. 2013. Capture and release of $\mathrm{CO}_{2}$ by polyamidine. J. Polym. Sci. A Polym. Chem. 51, 3404-3411.

Gebald, C. et al. 2013. Stability of Amine-Functionalized Cellulose during TemperatureVacuum-Swing Cycling for $\mathrm{CO}_{2}$ Capture from Air. Environ. Sci. Technol. 47, 10063-10070. 
Giri N. et al. 2015. Liquids with permanent porosity. Nature 527, 216-221.

Global Warming. 2015. The Business of Cooling the Planet. Available Online: http://fortune.com/2011/10/07/the-business-of-cooling-the-planet/ (accessed on $3^{\text {rd }}$ November 2015).

Goeppert, A. et al. 2010. Nanostructured silica as a support for regenerable highcapacity organoamine-based $\mathrm{CO}_{2}$ sorbents. Energy Environ. Sci. 2010, 1949-1960.

Goeppert, A. et al. 2011. Carbon Dioxide Capture from the Air Using a Polyamine Based Regenerable Solid Adsorbent. J. Am. Chem. Soc. 133, 20164-20167.

Goeppert, A. et al. 2012. Air as the renewable carbon source of the future: an overview of $\mathrm{CO}_{2}$ capture from the atmosphere. Energy \& Environmental Science 5, 7833-7853.

Hardie, S. M. L. et al. 2005. Carbon dioxide capture using a zeolite molecular sieve sampling system for isotopic (13C and 14C) studies of respiration. Radiocarbon 47, 441-451.

Heldebrant, D. J. et al. 2008. Organic liquid $\mathrm{CO}_{2}$ capture agents with high gravimetric $\mathrm{CO}_{2}$ capacity. Energy Environ. Sci. 1, 487-493.

Heydari-Gorji, A. et al. 2011. Degradation of amine-supported $\mathrm{CO}_{2}$ adsorbents in the presence of oxygen-containing gases. Microporous Mesoporous Mater.145, 146-149.

Heydari-Gorji, A. et al. 2012. Thermal, Oxidative, and $\mathrm{CO}_{2}$-Induced Degradation of Supported Polyethylenimine Adsorbents. Ind. Eng. Chem. Res. 51, 6887-6894.

Holewinski, A. et al. 2015. Linking $\mathrm{CO}_{2}$ Sorption Performance to Polymer Morphology in Aminopolymer/Silica Composites through Neutron Scattering. J. Am. Chem. Soc. 137, 1174911759.

Holmes, G. et al. 2013. Outdoor Prototype Results for Direct Atmospheric Capture of Carbon Dioxide. Energy Procedia 37, 6079-6095.

Huang, Z. et al. 2009. A novel application of the SAWD-Sabatier-SPE integrated system for $\mathrm{CO}_{2}$ removal and $\mathrm{O}_{2}$ regeneration in submarine cabins during prolonged voyages. J. Zhejiang Univ., Sci., A, 10, 1642-1650.

International Energy Agency (IEA) Statistics (2014), $\mathrm{CO}_{2}$ Emissions from Fuel Combustion 2014. Highlights, OECD/IEA, Paris. https://www.iea.org/publications/freepublications/publication/CO2EmissionsFromFuelCombusti onHighlights2014.pdf

Jiang, J.-X.; Cooper, A. I. 2010. Microporous organic polymers: design, synthesis, and function. Top Curr. Chem. 1-33.

Jones, C. W. 2011. $\mathrm{CO}_{2}$ capture from dilute gases as a component of modern global carbon management. Annu. Rev. Chem. Biomol. Eng. 2, 31-52. 
Keith, D. W., Ha-Doung, M., Stolaroff, J. K. 2006. Climate Strategy with $\mathrm{CO}_{2}$ Capture from the Air. Clim. Change 74, 17-45.

Keith, D. W., Heidel, K., Cherry, R. 2010. Capturing $\mathrm{CO}_{2}$ from the atmosphere: rationale and Process Design Considerations. In: Launder, B., Thompson, M., editors. Geo-Engineering Climate Change: Environmental necessity or Pandora's box? Cambridge University Press; P. 107-126.

Kharecha, P. A., Hansen, J. E. 2008. Implications of "peak oil" for atmospheric $\mathrm{CO}_{2}$ and climate. Global Biogeochemical Cycles 22, GB3012, 1-10.

Kothandaraman, J. et al. 2016. Conversion of $\mathrm{CO}_{2}$ from Air into Methanol Using a Polyamine and a Homogeneous Ruthenium Catalyst. J. Am. Chem. Soc. 138, 778-781.

Krishna, R., Calero, S., Smit, B. 2002. Investigation of entropy effects during sorption of mixtures of alkanes in MFI zeolite. Chem. Eng. J. 88, 81-94.

Krishna, R., van Baten, J. M. 2011. In silico screening of metal-organic frameworks in separation applications. Phys. Chem. Chem. Phys. 13, 10593-10616.

Krungleviciute, V. et al. 2012. $\mathrm{CO}_{2}$ Adsorption on Dahlia-Like Carbon Nanohorns: Isosteric Heat and Surface Area Measurements. J. Phys. Chem. C 116, 306-310.

Krungleviciute, V. et al. 2013. Neon and $\mathrm{CO}_{2}$ Adsorption on Open Carbon Nanohorns. Langmuir 29, 9388-9397.

Kumar, A. et al. 2015. Direct Air Capture of $\mathrm{CO}_{2}$ by Physisorbent Materials. Angew. Chem. Int. Ed. 54, 14372-14377.

Lackner, K. S., Ziock, H.-J., Grimes, P. 1999. Capturing Carbon Dioxide From Air. https://www.netl.doe.gov/publications/proceedings/01/carbon_seq/7b1.pdf.

Lackner, K. S., Sachs, J. D. 2005. A Robust Strategy for Sustainable Energy. Brookings Pap. Econ. Act. 2, 215-284.

Lackner, K. S. et al. 2012. The urgency of the development of $\mathrm{CO}_{2}$ capture from ambient air. Proceedings of the National Academy of Sciences 109, 13156-13162.

Li, H. et al. 1999. Design and synthesis of an exceptionally stable and highly porous metalorganic framework. Nature 402, 276-279.

Li, W. et al. 2010. Steam-Stripping for Regeneration of Supported Amine-Based $\mathrm{CO}_{2}$ Adsorbents. ChemSusChem 3, 899-903.

Li, W. et al. 2010. Structural Changes of Silica Mesocellular Foam Supported AmineFunctionalized $\mathrm{CO}_{2}$ Adsorbents Upon Exposure to Steam. ACS Appl. Mater. Interfaces 2, 33633372. 
Lin, L.-C. et al. 2012. In silico screening of carbon-capture materials. Nature Materials 11, 633641.

Liu, F.-Q. et al. 2015. Covalent grafting of polyethyleneimine on hydroxylated three-dimensional graphene for superior $\mathrm{CO}_{2}$ capture. J. Mater. Chem. A. 3, 12252-12258.

Lu, W. et al. 2013. Carbon Dioxide Capture from Air Using Amine-Grafted Porous Polymer Networks. J. Phys. Chem. C 117, 4057-4061.

Ludwinowicz, J., Jaroneic, M. 2015. Effect of activating agents on the development of microporosity in polymeric-based carbon for $\mathrm{CO}_{2}$ adsorption. Carbon 94, 673-679.

Lunn, J.D., Shantz, D. F. 2009. Peptide Brush - Ordered Mesoporous Silica Nanocomposite Materials. Chem. Mater. 21, 3638-3648.

Lund, H. 2007. Renewable energy strategies for sustainable development. Energy 32, 912-919.

Mahmoudkhani, M., Keith, D. W. 2009. Low-energy sodium hydroxide recovery for $\mathrm{CO}_{2}$ capture from atmospheric air-Thermodynamic analysis. Int. J. Greenh. Gas Control 3, 376-384.

Martin, C. F. et al. 2011. Microporous phenol-formaldehyde resin-based adsorbents for precombustion $\mathrm{CO}_{2}$ capture. Fuel 90, 2064-2072.

Matty, C. 2008. Overview of Long-Term Lithium Hydroxide Storage Aboard the Inetrnational Space Station, SAE Technical Paper 2008-0101969, presented at the International Conference on Environmental Systems, June 2008, San Francisco, USA.

McDonald, T. M. et al. 2012. Capture of carbon dioxide from air and flue gas in the alkylamineappended metal-organic framework mmen-Mg2(dobpdc). J. Am. Chem. Soc. 134, 7056-7065.

McNamara, N. D., Hicks, J. C. $\mathrm{CO}_{2}$ Capture and Conversion with a Multifunctional Polyethyleneimine-Tethered Iminophosphine Iridium Catalyst/Adsorbent. ChemSusChem 7, 1114-1124.

Myers, A. L., Prausnitz, J. M. 1965. Thermodynamics of mixed-gas adsorption. AIChE J. 11, 121-127.

Nandi, M. et al. 2012. Unprecedented $\mathrm{CO}_{2}$ uptake over highly porous $\mathrm{N}$-doped activated carbon monoliths prepared by physical activation. Chem. Commun. 48, 10283-10285.

NASA, NOAA Find 2014 Warmest in Modern Record. Available online: https://www.nasa.gov/press/2015/january/nasa-determines-2014-warmest-year-in-modern-record (accessed on $4^{\text {th }}$ December, 2015).

Nie, X., Kulkarni, A., Sholl, D. S. 2015. Computational Prediction of Metal Organic Frameworks Suitable for Molecular Infiltration as a Route to Development of Conductive Materials. J. Phys. Chem. Lett. 6, 1586-1591.

Norfleet, W., Horn, W. 2003. Carbon dioxide Scrubbing Capabilities of Two New Non-Powered Technologies, NSMRL Report No. TR1228, Naval Submarine Medical Research Laboratory (NSMRL). 
Nugent, P. et al. 2013. Porous materials with optimal adsorption thermodynamics and kinetics for $\mathrm{CO}_{2}$ separation.. Nature 495, 80-84.

Pasel, J. P. R., Specht, M. 2000 in Forshungsverbund Sonnenenergie, Themen 1999-2000: Zukunftstechnologie Breenstoffzelle, Berlin, Germany, 2000, p.46.

Przepiorski, J. et al. 2004. High temperature ammonia treatment of activated carbon for enhancement of $\mathrm{CO}_{2}$ adsorption. Appl. Surf. Sci. 225, 235-242.

Puretzky, A. A. et al. 2008. Cumulative and continuous laser vaporization synthesis of single wall carbon nanotubes and nanohorns. Appl. Phys. A Mater. Sci. Process. 93, 849-855.

Qi, G., Fu, L., Giannelis, E. P. 2014. Sponges with covalently tethered amines for highefficiency carbon capture. Nat. Commun. 5, 5796-6802.

Ranjan, M. 2010. Feasibility of Air Capture. MIT Masters Thesis. Available Online: https://sequestration.mit.edu/pdf/ManyaRanjan_Thesis_June2010.pdf (accessed on 28th January, 2016).

Ranjan, M., Herzog, H. J. 2011. Feasibility of air capture. Energy Proc. 4, 2869-2876.

Rodriguez-Reinoso, F. 2006. Porous carbons in gas separation and storage. Loureiro, J.M.; Kartel, M. T. (Eds.), Combined and hybrid adsorbents, NATO security through science series, vol.25 Springer, Netherlands, pp. 133-144.

Rowsell, J. L. C. et al. 2005. Gas Adsorption Sites in a Large-Pore Metal-Organic Framework. Science 309, 1350-1354.

Satyapal, S. et al. 2001. Performance and Properties of a Solid Amine Sorbent for Carbon Dioxide Removal in Space Life Support Applications. Energy Fuels 15, 250-255.

Sayari, A., Belmabkhout, Y., Serna-Guerrero, R. 2011. Flue gas treatment via $\mathrm{CO}_{2}$ adsorption. Chem. Eng. J. 171, 760-774.

Sayari, A. et al. 2012. $\mathrm{CO}_{2}$-Induced Degradation of Amine-Containing Adsorbents: Reaction Products and Pathways. J. Am. Chem. Soc. 134, 13834-13842.

Seema, H. et al. 2014. Highly selective $\mathrm{CO}_{2}$ capture by S-doped microporous carbon materials. Carbon 66, 320-326.

Serna-Guerrero, R. et al. 2010. Influence of regeneration conditions on the cyclic performance of amine-grafted mesoporous silica for $\mathrm{CO}_{2}$ capture: An experimental and statistical study. Chem. Eng. Sci. 65, 4166-4172.

Sevilla, M., Parra, J. B., Fuertes, A. B. 2013. Assessment of the Role of Micropore Size and NDoping in $\mathrm{CO}_{2}$ Capture by Porous Carbons. ACS Appl. Mater. Interfaces 2013, 5, 6360-6368.

Shafeeyan, M. S. et al. 2011. Ammonia modification of activated carbon to enhance carbon dioxide adsorption: effect of pre-oxidation. Appl. Surf. Sci. 257, 3936-3942. 
Shekhah, O. et al. 2014. Made-to-order metal-organic frameworks for trace carbon dioxide removal and air capture. Nat. Commun. 5, 4228-4334.

Shin, H. et al. 2015. Covalent Functionalization of Boron Nitride Nanotubes via Reduction Chemistry. ACS Nano 9, 12573-12582.

Solomon, S. et al. 2009. Irreversible climate change due to carbon dioxide emissions. PNAS 106, 1704-1709.

Specht, M. B., A. 1995. in Forshungsverbund Sonnenenergie, Themen 1994-1995, Energiespeicherung, p.41.

Specht M and Bandi A. The Methanol cycle - sustainable supply of liquid fuels. 1999. Stuttgart, Germany: Centre for Solar Energy and Hydrogen Research (ZSW); 1999.

Stuckert, N. R., Yang, R. T. 2011. $\mathrm{CO}_{2}$ Capture from the Atmosphere and Simultaneous Concentration Using Zeolites and Amine-Grafted SBA-15. Environ. Sci. Technol. 45, 1025710264.

Sumida, K. et al. 2012. Carbon dioxide capture in metal-organic frameworks. Chem. Rev. 112, 724-781.

Sun, N. et al. 2015. Solid adsorbents for low-temperature $\mathrm{CO}_{2}$ capture with low-energy penalties leading to more effective integrated solutions for power generation and industrial processes. Front. Energy Res. 3, 1-16.

Sun, N. N. et al. 2013. Synthesis, characterization and evaluation of activated spherical carbon materials for $\mathrm{CO}_{2}$ capture. Fuel 113, 854-862.

Sun, Q. et al. 2013. Charge-Controlled Switchable $\mathrm{CO}_{2}$ Capture on Boron Nitride Nanomaterials. J. Am. Chem. Soc. 135, 8246-8253.

Tan, X. et al. 2015. Conductive Graphitic Carbon Nitride as an Ideal Material for Electrocatalytically Switchable $\mathrm{CO}_{2}$ Capture. Scientific Reports 5, 17636.

Tenebaum, D. J. 2009. Biochar: Carbon Mitigation from the Ground Up. Environ Health Perspect. 117, A70-A73.

Terlain, A., Larher, Y. 1983. Phase diagrams of films of linear molecules with large quadrupole moments $\left(\mathrm{CO}_{2}, \mathrm{~N}_{2} \mathrm{O}, \mathrm{C}_{2} \mathrm{~N}_{2}\right)$ adsorbed on graphite. Surf. Sci. 125, 304-311.

Thomson, A. 2015 May Just Be Hottest Year on Record. Scientific American. Available Online: http://www.scientificamerican.com/article/2015-may-just-be-hottest-year-on-record/ (accessed on $4^{\text {th }}$ February, 2016). 
To, J. W. F. To et al. 2016. Hierarchical N-Doped Carbon as $\mathrm{CO}_{2}$ Adsorbent with High $\mathrm{CO}_{2}$ Selectivity from Rationally Designed Polypyrrole Precursor. J. Am. Chem. Soc. 138, 10011009.

Walton, K. S., Sholl, D. S. 2015. Predicting multicomponent adsorption: 50 years of the ideal adsorbed solution theory. AlChe J. 61, 2757-2762.

Wang, T., Lackner, K. S., Wright, A. B. 2013. Moisture-swing sorption for carbon dioxide capture from ambient air: a thermodynamic analysis. Phys. Chem. Chem. Phys. 15, 504-514.

Wang, T. et al. 2016. Preparation and kinetics of a heterogeneous sorbent for $\mathrm{CO} 2$ capture from the atmosphere. Chem. Eng. J. 284, 679-686.

Wilfong, W. C., Kail, B. W., Gray, M. L. 2015. Rapid Screening of Immobilized Amine CO2 Sorbents for Steam Stability by Their Direct Contact with Liquid $\mathrm{H}_{2} \mathrm{O}$. ChemSusChem 8, 20412045.

Woolf, D. et al. 2010. Sustainable biochar to mitigate global climate change. Nat. Commun. 1, 56-64.

Wurzbacher, J. A. et al. 2011. Separation of $\mathrm{CO}_{2}$ from air by temperature-vacuum swing adsorption using diamine-functionalized silica gel. Energy Environ. Sci. 4, 3584-3592.

Xue, D. X. et al. 2013. Tunable rare-earth fcu-MOFs: a platform for systematic enhancement of $\mathrm{CO}_{2}$ adsorption energetics and uptake. J. Am. Chem. Soc. 135, 7660-7667.

Yuan, D. et al. 2011. Highly Stable Porous Polymer Networks With Exceptionally High GasUptake Capacities. Adv. Mater. 23, 3723-3725.

Zhao, Y. F. et al. 2012. Novel porous carbon materials with ultrahigh nitrogen contents for selective $\mathrm{CO}_{2}$ capture. J. Mater. Chem. 22, 19726-19731.

Zhao, X. et al. 2004. Hysteretic Adsorption and Desorption of Hydrogen by Nanoporous MetalOrganic Frameworks. Science 306, 1012-1015.

Zhong, M. J. et al. 2012. Copolymer-templated nitrogen-enriched porous nanocarbons for $\mathrm{CO}_{2}$ capture. Chem. Commun. 48, 11516-11518. 